\title{
Whole exome sequencing in three families segregating a pediatric case of sarcoidosis
}

\author{
Alain Calender ${ }^{1,3^{*}}$ (D), Pierre Antoine Rollat Farnier ${ }^{2}$, Adrien Buisson ${ }^{1}$, Stéphane Pinson ${ }^{1}$, Abderrazzaq Bentaher ${ }^{3}$, \\ Serge Lebecque ${ }^{4}$, Harriet Corvol ${ }^{5}$, Rola Abou Taam ${ }^{6}$, Véronique Houdouin ${ }^{7}$, Claire Bardel ${ }^{2}$, Pascal Roy ${ }^{2}$, \\ Gilles Devouassoux ${ }^{8}$, Vincent Cottin ${ }^{9}$, Pascal Seve ${ }^{10}$, Jean-François Bernaudin ${ }^{11}$, Clarice X. Lim ${ }^{12}$, \\ Thomas Weichhart ${ }^{12}$, Dominique Valeyre ${ }^{13,14}$, Yves Pacheco ${ }^{3}$, Annick Clement ${ }^{15}$, \\ and Nadia Nathan ${ }^{15}$ in the frame of GSF (Groupe Sarcoïdose France)
}

\begin{abstract}
Background: Sarcoidosis (OMIM 181000) is a multi-systemic granulomatous disorder of unknown origin. Despite multiple genome-wide association (GWAS) studies, no major pathogenic pathways have been identified to date. To find out relevant sarcoidosis predisposing genes, we searched for de novo and recessive mutations in 3 young probands with sarcoidosis and their healthy parents using a whole-exome sequencing (WES) methodology.

Methods: From the SARCFAM project based on a national network collecting familial cases of sarcoidosis, we selected three families (trios) in which a child, despite healthy parents, develop the disease before age $15 \mathrm{yr}$. Each trio was genotyped by WES (Illumina HiSEQ 2500) and we selected the gene variants segregating as 1) new mutations only occurring in affected children and 2) as recessive traits transmitted from each parents. The identified coding variants were compared between the three families. Allelic frequencies and in silico functional results were analyzed using ExAC, SIFT and Polyphenv2 databases. The clinical and genetic studies were registered by the ClinicalTrials.gov - Protocol Registration and Results System (PRS) (https://clinicaltrials.gov) receipt under the reference NCT02829853 and has been approved by the ethical committee (CPP LYON SUD EST - 2 - REF IRB 00009118 - September 21, 2016).

Results: We identified 37 genes sharing coding variants occurring either as recessive mutations in at least 2 trios or de novo mutations in one of the three affected children. The genes were classified according to their potential roles in immunity related pathways: 9 to autophagy and intracellular trafficking, 6 to G-proteins regulation, 4 to T-cell activation, 4 to cell cycle and immune synapse, 2 to innate immunity. Ten of the 37 genes were studied in a bibliographic way to evaluate the functional link with sarcoidosis.

Conclusions: Whole exome analysis of case-parent trios is useful for the identification of genes predisposing to complex genetic diseases as sarcoidosis. Our data identified 37 genes that could be putatively linked to a pediatric form of sarcoidosis in three trios. Our in-depth focus on 10 of these 37 genes may suggest that the formation of the characteristic lesion in sarcoidosis, granuloma, results from combined deficits in autophagy and intracellular trafficking (ex: Sec16A, AP5B1 and RREB1), G-proteins regulation (ex: OBSCN, CTTND2 and DNAH11), T-cell activation (ex: IDO2, IGSF3), mitosis and/or immune synapse (ex: SPICE1 and KNL1). The significance of these findings needs to be confirmed by functional tests on selected gene variants.
\end{abstract}

Keywords: Sarcoidosis, Whole-exome sequencing (WES), Sarcoidosis, Candidate genes

\footnotetext{
* Correspondence: alain.calender@chu-lyon.fr

1 Genetics Department, Hospices Civils de LYON (HCL), University Hospital,

East Pathology Center, LYON, B-A3, 59 Bld Pinel, 69677 BRON Cedex, France

${ }^{3}$ Inflammation \& Immunity of the Respiratory Epithelium - EA7426 (PI3) -

South Medical University Hospital - Lyon 1 Claude Bernard University, 165

Chemin du Grand Revoyet, 69310 Pierre-Bénite, France

Full list of author information is available at the end of the article
}

(c) The Author(s). 2018 Open Access This article is distributed under the terms of the Creative Commons Attribution 4.0 International License (http://creativecommons.org/licenses/by/4.0/), which permits unrestricted use, distribution, and reproduction in any medium, provided you give appropriate credit to the original author(s) and the source, provide a link to the Creative Commons license, and indicate if changes were made. The Creative Commons Public Domain Dedication waiver (http://creativecommons.org/publicdomain/zero/1.0/) applies to the data made available in this article, unless otherwise stated. 


\section{Background}

Sarcoidosis is an enigmatic multisystem disease characterized by the development and accumulation of granulomas, a compact collection of macrophages which have differentiated into epithelioid and multinucleated giant cells associated with lymphocytes [1]. The disease is considered to be the consequence of granulomatous reaction after exposure to various antigens and/or mineral particles in individuals with a susceptible genetic background [1, 2]. Sarcoidosis may be a chronic, benign or fatal disease affecting mainly lungs, skin, eyes and various other organs. This inflammatory disease develops before the age of 50 years and its incidence varies around the world with the highest frequencies being found in Northern European countries (10 to 40 per 100.000) [1]. In children, sarcoidosis is a very rare disease with an estimated prevalence of 0.4 to 1.2 per 100.000 [3]. A recent French study on a series of 41 children with sarcoidosis provided updated information on the initial presentation, the management and the follow-up of the disease [4]. It affects mainly children older than 10 years, while one third of them are younger. The disease is often severe with general symptoms at the forefront (asthenia, fever) and multiple organs involved at diagnosis in $85 \%$ of the children. The evolution is marked by frequent relapses and at risk to lung fibrosis despite extensive corticosteroid and immunosuppressive treatments [5]. The relative contribution of genetic and environmental factors is unknown but an 80-times increase in risk for monozygotic twins suggests that genetic factors might account for $50-60 \%$ of the disease susceptibility [6]. Sarcoidosis is commonly sporadic with familial presentation occurring in $3-5 \%$ of cases. The pedigree analysis suggests an autosomal dominant mode with incomplete penetrance. The French National SARCFAM study, based on a clinical network including 29 clinical centers, allowed the collection of clinical data and DNA samples of a cohort of 140 families with at least two firstdegree relatives affected by sarcoidosis and rare situations of nuclear families with pediatric cases [7]. We gave priority consideration to the analysis of pediatric clinical situations in which the child with sarcoidosis has healthy parents, ie trios, expecting that new mutations and /or gene variants transmitted on a recessive pattern may highlight specific genetic pathways involved in the disease. Initially the genetic studies were focused on the genes previously identified by GWAS as putative pathogenic determinants in the risk of sarcoidosis. One of candidate gene, BTNL2, codes a cofactor of CD86, a regulator of Tcell activation, and a BTNL2 rs2076530 SNP splicing variant has been shown to induce an $\approx 2.0$ fold increase in risk of occurrence of the disease $[7,8]$. However, we have previously shown that this variant did not discriminate the sporadic and familial forms of the disease, thus suggesting BTNL2 is not a major gene predisposing to sarcoidosis
[7]. GWAS studies in several series have identified SNP's directly or indirectly implicated in innate immunity, such as HLADRB, CCDC88B, ANNEXINA11 (ANXA11), XAF1 and other candidate loci [9]. Granuloma formation is a process with hypothesized immune synapse abnormalities, suggesting new trials for treatment that target B and/ or T cells [10]. A remarkable feature of sarcoidosis is the compartmentalization of CD4 (+) T helper 1 (Th1) lymphocytes and activated macrophages in the affected organs to initiate the formation and maintenance of granulomas [11]. Another subset of T-cells, Th17 effector CD4 (+), which mediate the crosstalk between immune cells and tissues, has been shown to participate in the progression of granulomas and in the fibrotic phase of the disease. A third subgroup of immune cells, the CD4 (+) CD25 (+) regulatory $\mathrm{T}$ cell (Treg) showed an abnormal expansion which may be responsible for the paradoxical suppression of the immune response to tuberculin observed in sarcoidosis [12]. Taken together, the immune pattern in sarcoidosis is close to that observed in other Th1/Th17 related diseases, as tuberculosis, leprosy, chronic beryllium disease (CBD), ulcerative colitis or Crohn disease but molecular signals that control granuloma genesis are largely undefined. A series of data obtained from animal models suggested a triggering of granuloma formation by mineral pollutants such as carbon nanotubes [13]. On the molecular side, several previous biochemical studies have shown abnormalities in pathways involving NF B [14], STAT1 [15], Gai [16], and RIP2/IRAK [17], highlighting the difficulty of targeting a specific signalling pathway for therapeutic purposes. It was recently shown that the constitutive activation of mTORC1 in a mouse model deficient for TSC2 promotes granuloma formation through a metabolic reprogramming mediated by CDK4, suggesting a crucial role of the TSC1/TSC 2 complex and mTor pathway in granulomatous diseases [18]. Nevertheless, identifying the genes which might be related to familial predisposition remains challenging as sarcoidosis is considered as a complex multifactorial disease involving a synergistic effect of many genes carrying either rare and more common variants. Our working hypothesis that we have tested here is that a comparative WES analysis of children affected early in life by a serious form of sarcoidosis and both their unaffected parents (trio analysis) may identify de novo and recessive genetic variants that could potentially point to pathways acting alone or in combination in disease development.

\section{Methods}

Patient recruitment, clinical evaluation, and sample collection

We recruited 3 trios, defined by a pediatric case of sarcoidosis and their unaffected parents. The clinical data were retrieved through the reference center for rare lung 
diseases (RespiRare) network and samples were collected in the frame of the SARCFAM project which involved 28 French university departments of internal medicine and/or pulmonology. The genetic project has ethical committee approval (CPP SUD EST - 2 - IRB 00009118 - September 21, 2016) and the clinical and genetic studies are registered by the ClinicalTrials.gov- Protocol Registration and Results System (PRRS) Receipt under the reference NCT02829853.

\section{Trio 1 (T1), reported in $[3,19]$}

An 8-year-old girl presented with massive and painful splenomegaly, deep pancytopenia, and mild systemic inflammation. Her parents were healthy and nonconsanguineous. A bone marrow biopsy revealed epithelioid granulomas, leading to consider the diagnosis of a granulomatous disease. She had an increased plasma concentration of angiotensin converting enzyme (ACE) and bilateral hilar and mediastinal enlarged lymph nodes with several lung nodules on the lung CT scan. Pulmonary function tests showed a decreased dynamic lung compliance with normal blood gases and $\mathrm{CO}$ transfer. The bronchoalveolar lavage (BAL) showed an increased total cell count with 50\% lymphocytes with a CD4/CD8 ratio of 5.4. No mutation of the NOD2/CARD15 gene was detected. She was treated by monthly methylprednisolone pulses in association with daily oral prednisone therapy. Her general condition improved and, 6 months later, complete blood count was normal, splenomegaly, hilar lymphadenopathies and the pulmonary nodules had significantly decreased. During the following 7 years, she presented multiple relapses that remain corticosteroid-sensitive. A methotrexate treatment was started and she is currently under evaluation.

\section{Trio 2 (T2)}

The diagnosis of sarcoidosis was made in a 6-year-old boy presenting with fever, weight-loss and tiredness. He also suffered from dyspnea, obstructive sleep snoring and apnea related to laryngeal and tonsil infiltration. Endoscopic examination revealed laryngeal infiltrates and pulmonary CT scan pulmonary infiltrates. Transbronchial biopsies allowed the identification of characteristic epithelioid granuloma and inflammatory related lesions. He was treated by 3 pulses of methylprednisolone followed by a 1 year treatment with oral prednisolone. The evolution was regressive with the absence of complications or symptomatic expression to date. Recent examinations by X-ray, CT-scan and pulmonary function tests were normal. His parents were healthy and a priori non-consanguineous. No mutation of the NOD2/CARD15 gene was detected.

\section{Trio 3 (T3)}

Sarcoidosis occurs in a young girl (age $5 \mathrm{yr}$ ) expressing a systemic disease with fever and pancytopenia, hepatomegaly and splenomegaly, mediastinal and peritoneal lymphadenopathies. Pulmonary CT-scan revealed extensive bilateral, hilar and mediastinal lymph node enlargement. Bronchoalveolar lavage (BAL) showed an increase of lymphocytes (50\%) with more than $90 \%$ of CD4+ T-lymphocytes. Salivary glands and medullary biopsies allowed the characterization of granulomas with epithelioid and giant cells without necrosis. The patient was treated with methylprednisolone for 1 year with disease recurrence observed 8 months after the end of the treatment. The evolution affected many organs, lungs, liver, spleen and kidneys, confirmed by a renal biopsy showing similar epithelioid and giant cells rich granulomas, without necrosis. Corticoid therapy was initiated, associated to immunosuppressive protocol using mofetilmycophenolate. The treatment has been modified since 1 year with decreasing doses of the immunosuppressive agent and recently, the patient was considered to be in a remission phase. No mutation of the NOD2/CARD15 gene was detected.

\section{Targeted exome sequencing}

Genomic DNA was captured using Agilent in-solution enrichment methodology (SureSelect Human Clinical Research Exome, Agilent) with the supplied biotinylated oligonucleotides probes library (Human Clinical Research Exome, Agilent), followed by paired-end 75 bases massively parallel sequencing on Illumina HiSEQ 4000 [20]. Sequence capture, enrichment and elution were performed according to manufacturer's instruction and protocols (SureSelect, Agilent) without modification except that library preparation was performed with NEBNext ${ }^{\circ}$ Ultra kit (New England Biolabs ${ }^{\circ}$ ). For library preparation $600 \mathrm{ng}$ of each genomic DNA was fragmented by sonication and purified to yield fragments of 150-200 bp. Paired-end adaptor oligonucleotides from the NEB kit were ligated on repaired, A-tailed fragments then purified and enriched by 8 PCR cycles. $1200 \mathrm{ng}$ of these purified libraries were then hybridized to the SureSelect oligo probe capture library for $72 \mathrm{~h}$. After hybridization, washing, and elution, the eluted fraction was PCR-amplified with 9 cycles, purified and quantified by QPCR to obtain sufficient DNA template for downstream applications. Each eluted-enriched DNA sample was then sequenced on an Illumina HiSEQ 4000 as paired-end $75 \mathrm{~b}$ reads. Image analysis and base calling is performed using Illumina Real Time Analysis (RTA 2.1.3) with default parameters. Library preparation, exome capture, sequencing and data analysis have been done by IntegraGen SA (Evry, France). 


\section{Bioinformatics}

Two independent bioinformatics analyses were conducted, for the purpose of reducing the risk of missing a variant of interest. Both used the hg19 assembly version of the human genome.

First, the Integragen $\odot$ pipeline was used. Reads were mapped using Elandv2e, and duplicates were removed. The variant call was performed using CASAVA1.8. Regions with low mappability (QVCutoff <90) and variants with a weak quality (10 for SNVs, 20 for indels), were filtered out.Variants were annotated with population databases (1000G, ESP, ExAC, plus an Integragen $\odot$ in-house database of exomes) and with score predictions (SIFT, Polyphen). Functional consequences of variants were predicted by Variant Effect Predictor. The familial analysis was done on each trio using Eris software (Integragen $\odot$ ).

Second, our in-house pipeline (PASS) was used that follows the recommendations of the Broad Institute (https:// www.broadinstitute.org/gatk/guide/best-practices). Reads were trimmed with Trimmomatic, and aligned using BWA-MEM. Duplicates were marked using PicardTools, and the alignments were realigned and recalibrated using GATK. The variant call and genotyping were performed using GATK HapoltypeCaller (gVCF mode) and GenotypeGVCFs. Then, variants were recalibrated using GATK VariantRecalibrator. Variant annotation was done by snpEff/SnpSift, using both population (1000 Genomes, ExAC) and pathogenicity score (SIFT, Polyphenv2, Mutation Taster) databases. The familial analysis was performed with genoFilter (an in-house script). For this purpose, GATK CalculateGenotypePosteriors was first used with a pedigree file of the trio in order to reassign genotypes and genotype qualities. Only variants with balanced allele frequencies (maximum of imbalance of $0.35 / 0.65)$, and a genotype quality superior to 20 were considered.

\section{Statistical and functional evaluation of variants in silico}

Gene sequences of the gene including known variations were downloaded from http://www.ensembl.org/ Homo_ sapiens/Transcript/Variation_Transcript/. Predicted consequences of genetic variations were evaluated by using online bioinformatics tools such as SIFT [21], PolyPhen-2 [22], and EX_Skip [23]. The same information is compiled in ALAMUT@ Visual software (from Interactive Biosoftware $($ ) which allows us to know if the variants observed have already been described in recessive or dominant genetic diseases. A statistical analysis has been performed on these scores. VCF files were annotated with the dbNSFP v3.5 database [24]. CADD (Combined Annotation Dependent Depletion) [25], SIFT and POLYPHEN ranked scores were recovered for the selected de novo and recessive variants and for all the variants in the same genes and in the same patients, a mean value of the scores was considered when variants affect several transcripts. The different scores being non-normally distributed, their median was compared in the two groups (selected de novo and recessive variant vs all other variants in the same genes) by a non-parametric Wilcoxon/MannWhitney test. To identify which pathways the deleterious variant carrying genes might be enriched in an over-representation gene enrichment KEGG pathway analysis was performed on all the deleterious variant carrying genes identified from $\mathrm{T} 1, \mathrm{~T} 2$ and $\mathrm{T} 3$ amongst total identified variant carrying genes using WebGestalt [26].

\section{Sanger sequencing for variants confirmation}

Primer oligonucleotides for polymerase chain reaction and DNA sequencing were located within the reference sequence for the SPICE1 and CASC5 (Knl1) gene and surrounding the c.1912 $\mathrm{T}>\mathrm{G}$ (SPICE1) and c.3853A $>\mathrm{G}$ (CASC5), respectively. For SPICE1 a 698 bp amplicon was produced and sequenced using primers $5^{\prime}$-CCATGGT GGGCTAATGAAATGA-3' and 5'-GCCAAACATAAGC CATCTAGCC-3'.

For CASC5 a 726 bp amplicon was produced and sequenced using primers 5'-AGATCACTAGGAGTCA CACAA-3' and 5' CTTCCTTCTCTAACAAAGGACA$3^{\prime}$. Agarose gel electrophoresis was used as a PCR quality control with size controls. The PCR products were then purified by Illustra ${ }^{\mathrm{Tm}}$ ExoProStar $^{\mathrm{Tm}}$. The sequencing was performed by Big Dye terminator v1.1 after purification with BigDye ${ }^{\oplus}$ XTerminator ${ }^{\mathrm{Ts}}$ Purification Kit. Sequence delineation and base calling used an automated fluorescent DNA sequencer (Applied Biosystems ${ }^{\mathrm{TM}}$, model 3130xl).

\section{Estimation of the inbreeding coefficient $(f)$}

Inbreeding coefficients for each individual of T1, T2 and T3 were estimated by using the FEstim method [27] implemented in the FSuite software [28]. FEstim is a maximum-likelihood method that takes marker dependencies into account through a hidden Markov model. It gives more-specific information about an individual's genome than the genealogy does, because it better reflects the true proportion of the individual's genome that is autozygous. To obtain unbiased estimates of the inbreeding coefficient (f), a set of markers in minimal linkage disequilibrium should be used. We thus used the set of around 33,000 common polymorphisms in European population recommended by FSuite's authors and drew 100 subsamples of around 3900 markers. The inbreeding coefficient was then estimated as the median value of the 100 estimates obtained on the different subsamples [28]. A likelihood ratio test is then performed in FEstim to identify whether individuals are inbred or not. 


\section{Results}

Inbreeding coefficient (f) of affected children (c) in trios 1, 2 and 3

Inbreeding coefficients were respectively $0 \quad(p=$ $0.975045)$ for T1c, $0.007(p=0.08312)$ for T2c and 0 for T3c $(p=0.97502)$. These data are suggestive of the absence of consanguinity in the three patients: the null hypothesis stating that the individuals are outbred is not rejected at the $5 \%$ level.

\section{WES sequencing and data selection}

As shown in Fig. 1, the total number of variants inherited as homozygous recessive in the affected children represents 431 variants for trio 1 (404 missense, 3 frame-shifts, 6 in frame insertions, 14 splice site, and 4 start or stop codons lost), 435 variants for trio 2 (409 missense, 1 nonsense, 5 frame shift, 7 in frame deletion / insertion, and 2 stop codons lost), and 515 variants for trio 3 (478 missense, 4 nonsense, 8 frame shift, 12 in frame deletion / insertion, 12 splice site and 1 stop lost). We observed only 6 de novo mutations / variants, occurring in 6 genes and respectively 2 for T1 (IGSF3 and SPICE1), 2 for T2 (ZNF717 and CTNND2), and 2 for T3 (NPHS2 and PRSS55) (Table 1). We did not find recurrence of specific de novo mutations between two trios. Taking into account all values of minor allele frequency (MAF), we observed 9 variants in 9 different genes expressed as recessive traits in at least 2 trios, and respectively Sec16A and ADGRV1 (T1+ T2), RHBDL2, ZNF804A, AP5B1, TYR and CPAMD8 (T1 + T3), PRSS48 (T2 + T3) and OR11G2 (T1 + T2 + T3) (Additional file 1: Table S1). We observed also 12 genes sharing variations in at least two trios, but with different intragenic locations between the three patients (Additional file 2: Table S2). This concerns $\mathrm{T} 1+\mathrm{T} 2$ (ASPN, WFDC3, CCT6B), T1 + T3 (OBSCN, SLC16A8), T2 + T3 (AFAP1, HSD17B4, DNAH11, CNGB1, MARCH10) and lastly T1 + T2 + T3 (RHBG, KNL1) for a total of 26 variants. We also took into account the possibility of composite heterozygocity which was observed in 11 genes, representing 44 variants and occurring in at least two trios: T1 + T2 (CMYA5, PCDHB16, RREB1), T1 + T3 (AIM1L, IDO2, KIR3DL1 and T2 + T3 (TDRD5, DNAH11, PIEZO1, FCGBP and PCNT) (Additional file 3: Table S3). By restricting MAFs to values less than 0.01, we identified 9 homozygous recessive variants occurring in a single trio (Table 2). This concerns five different genes for T1 (ZNF717, WNT2, GOG6, BEGAIN, NDUFV3), two for T2 (SHROOM1 and FMNL1) and two for T3 (DCP1B and CHRNA3).

\section{Statistical evaluation of prioritized variants}

We performed a Wilcoxon/Mann-Whitney test to compare the deleterious effect of the prioritized variants, i.e., SIFT, PolyPhen, and CADD rank scores, against the other variants within the same gene [25]. The data

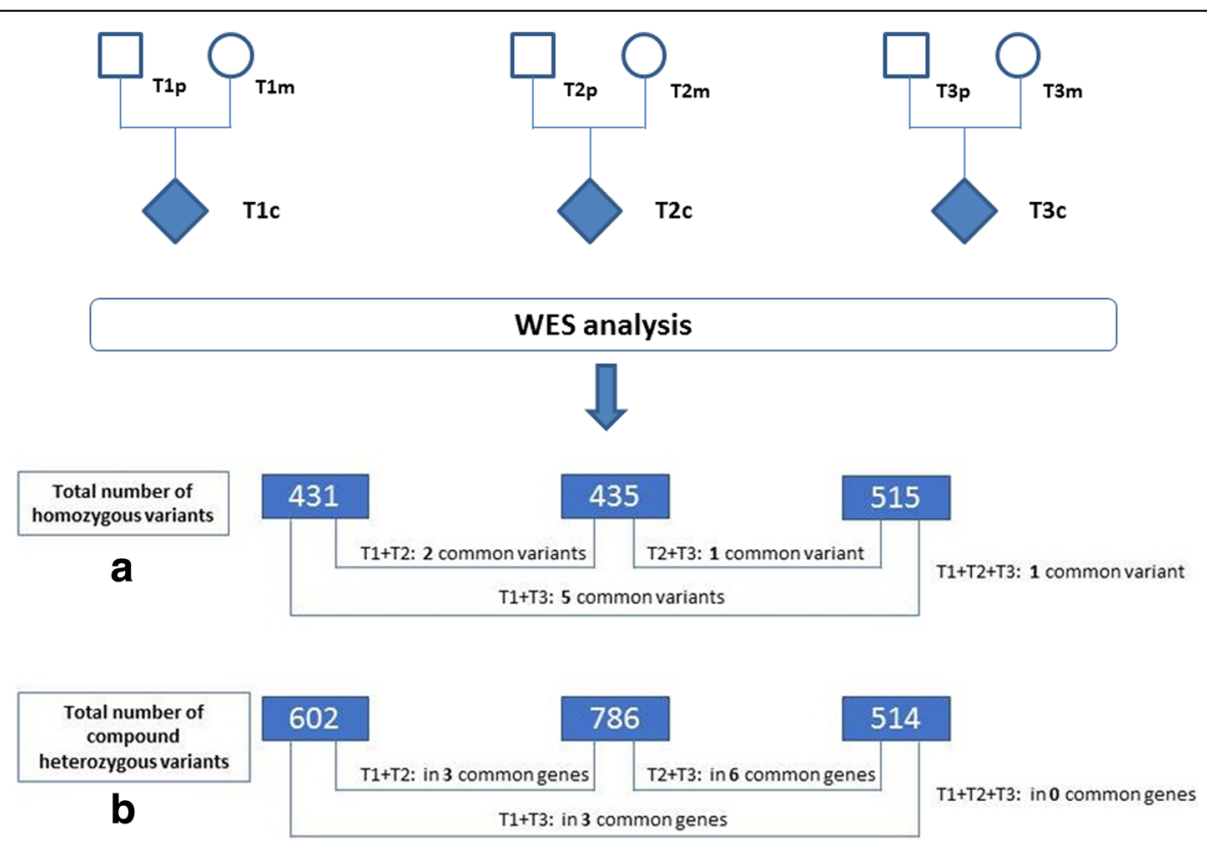

Fig. 1 Flowchart of WES (Whole Exome Sequencing) analysis: T1, T2, T3 design the three nuclear families respectively, $\mathrm{p}$ (paternal) for the father, $\mathrm{m}$ (maternal) for the maternal and $\mathrm{c}$ for the affected child. The number in dark boxes indicate the total number of variants identified respectively in T1, T2 and T3 and inherited in affected children as (a) homozygous and (b) compound heterozygous variants. As mentioned in the text, we selected only those variants which were observed in at least two trios and putatively pathogenic as suggested by SIFT and/or POLYPHENv2 software 


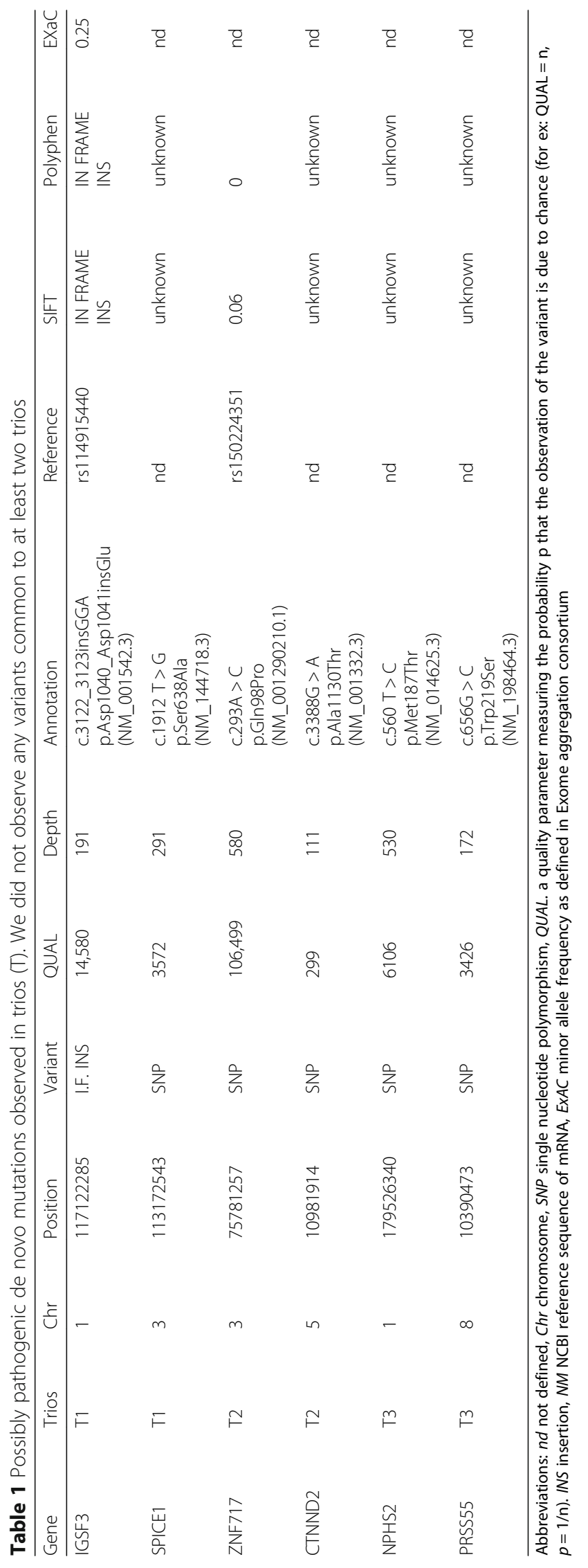




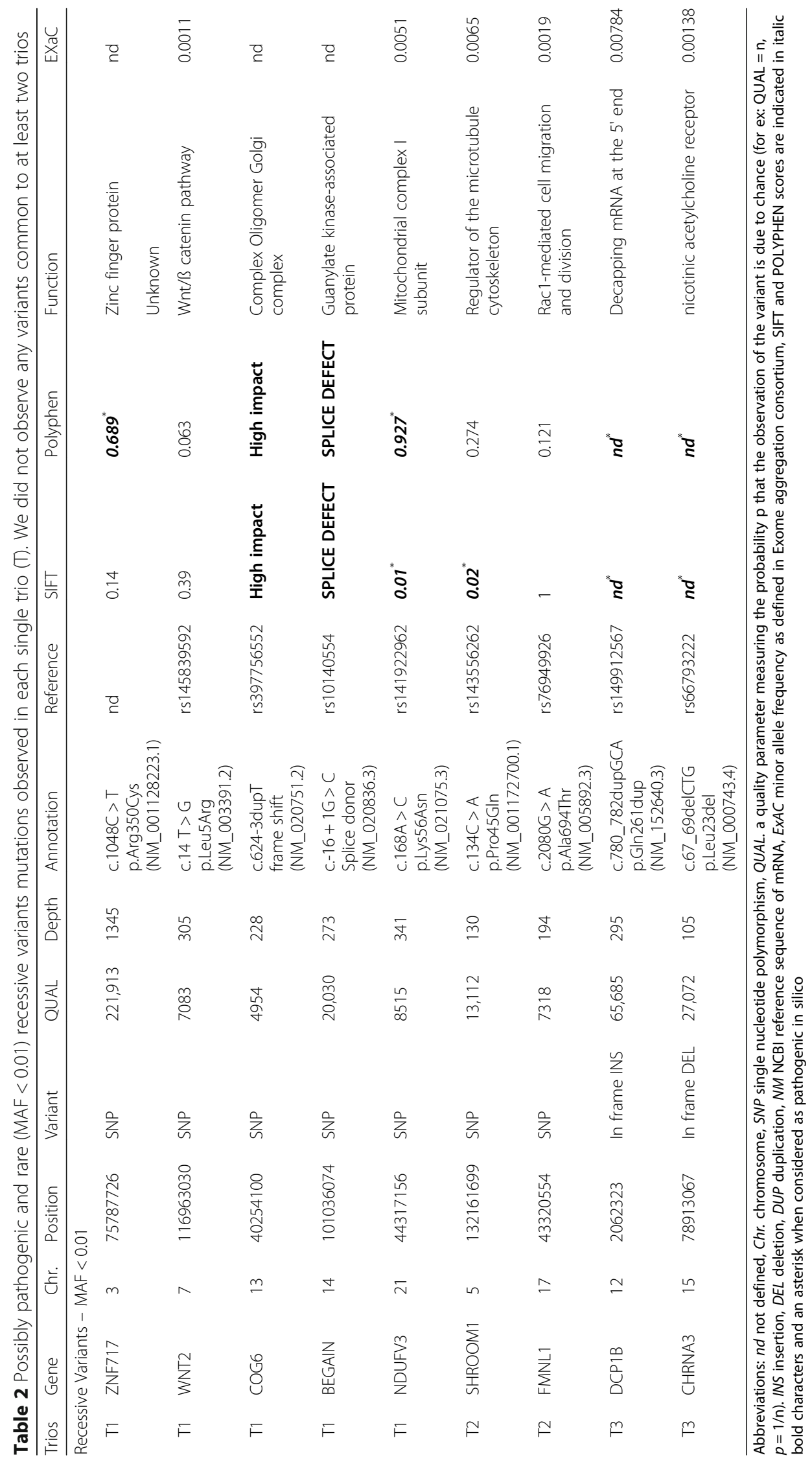


showed no statistical differences for SIFT (dbNSFP SIFT_rankscore: $p=0.4705$ ) and POLYPHEN (dbNSFP Polyphen2_HDIV_rankscore: $p=0.9322$ ). We observed a statistically significant difference for the CADD score (dbNSFP_CADD_phred: $p=0.008468$ ) (Additional file 4: Figure S1).

\section{Confirmation of variants and sanger sequencing}

As these results were only descriptive and not associated to functional tests, all the gene variants were analyzed for their putative functional effect on the encoded protein with the SIFT and PolyPhen-2 online softwares databases. The quality (QUAL) of variants were assessed by a mean depth value of 349 [88-1012] and a mean quality score of 24,521 [299-183,916], suggesting that on average, the probability that the observed variants are due to a random occurrence is less than 0,000042. As shown in Fig. 2a the variants occurring in SPICE1 and KNL1 (CASC5) as de novo and recessive respectively, the IGV (Integrative Genomics Profile) confirmed the specificity of these observations according to the parental and child genomic profiles. Lastly, for some of these variants, we performed Sanger sequencing to confirm the presence of the variants found by WES (Fig. 2b).

\section{Functional interpretation of variants related to gene} function

We based our in silico functional analysis on the putative pathogenicity of each variants, as suggested by SIFT and Polyphenv2 and then, an exhaustive search in PubMed (National Center for Biotechnology Information, U.S. National Library of Medicine) screening of published data linking a gene to immunity or related pathways. We performed an over-representation analysis of all deleterious variant carrying genes identified in T1, $\mathrm{T} 2$ and T3 probands amongst the list of total variant genes to find KEGG pathways that the deleterious genes might be enriched in. Interestingly, we found that these genes are enriched in pathways related to Antigen processing and presentation and that of the hematopoietic cell lineage (Additional file 5: Table S4). As shown in Table 3, among 37 genes, 10 (Sec16A, AP5B1, RREB-1, ASPN, RHBDL2, RHBG, KIR3DL1, TDRD5, MARCH10 and AFAP1) can be linked to autophagy and intracellular trafficking involving vesicles, Golgi apparatus and cytoskeleton, 6 genes (OBSCN, DNAH11, CTNND2, CNGB1 and NPHS2) play a direct or indirect role in Gprotein regulation, 4 genes (IDO2, IGSF3, PIEZO1 and HSD17B4) may be related to T-cell activation, 6 genes
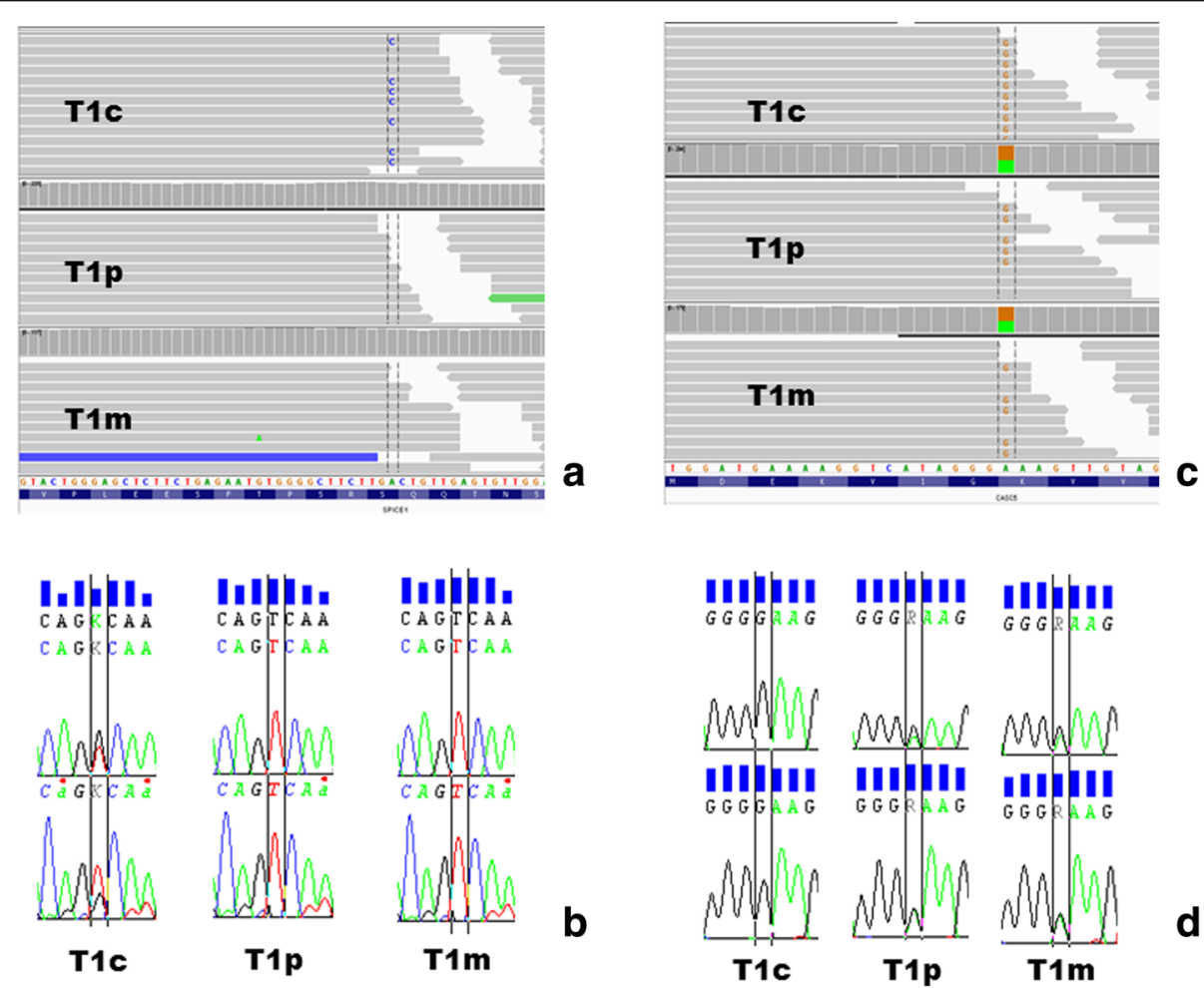

Fig. 2 Parallel visualization of two gene variants identified in T1 by Integrative Genomics Viewer (IGV) (Broad Institute@) and Sanger Sequencing $\mathbf{a}+\mathbf{b}$ Confirmation of the de novo c.1912 T > G (c.1912A > C on reverse strand by WES) variant in the SPICE1 gene inherited by T1c (a $+\mathbf{b})$, either on IGV (a) and Sanger sequence (b). c + d Confirmation of the homozygous c.2806A > G variant in the KNL1 (CASC5) gene inherited by T1c, either on IGV (c) and Sanger sequence $(\mathbf{d})$. The IGV profiles show the absence of c.1912 T> G (SPICE1) in both T1p and T1 $\mathrm{m}$ parents (a) and the status of heterozygous carriers of T1p and T1 $m$ for the c.2806A > G (KNL1) variant (c) 


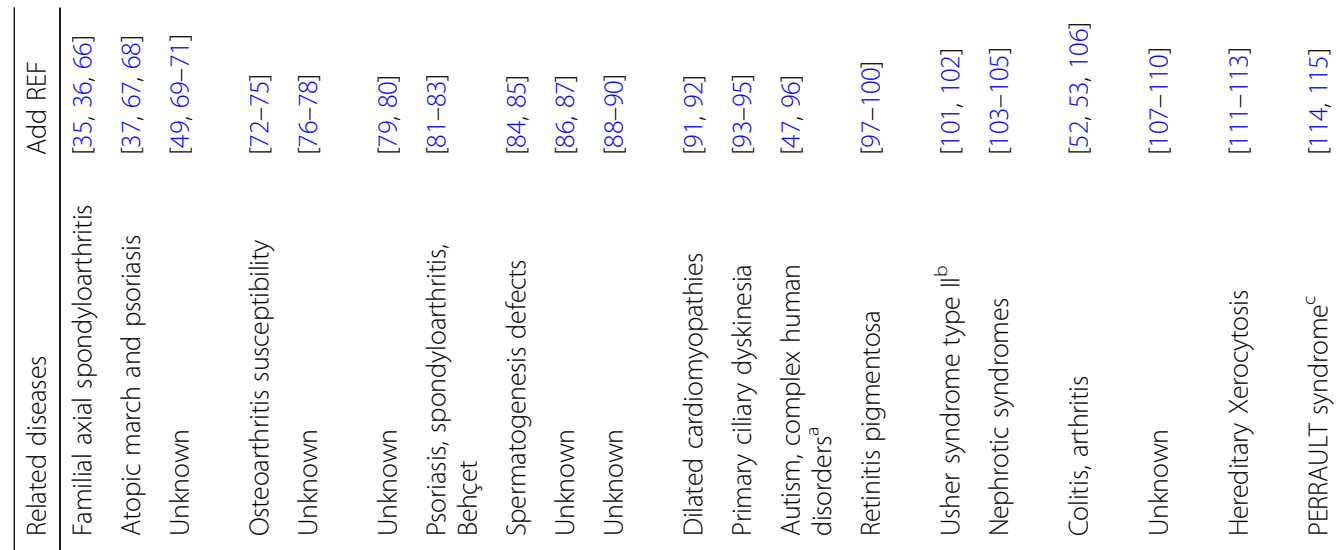

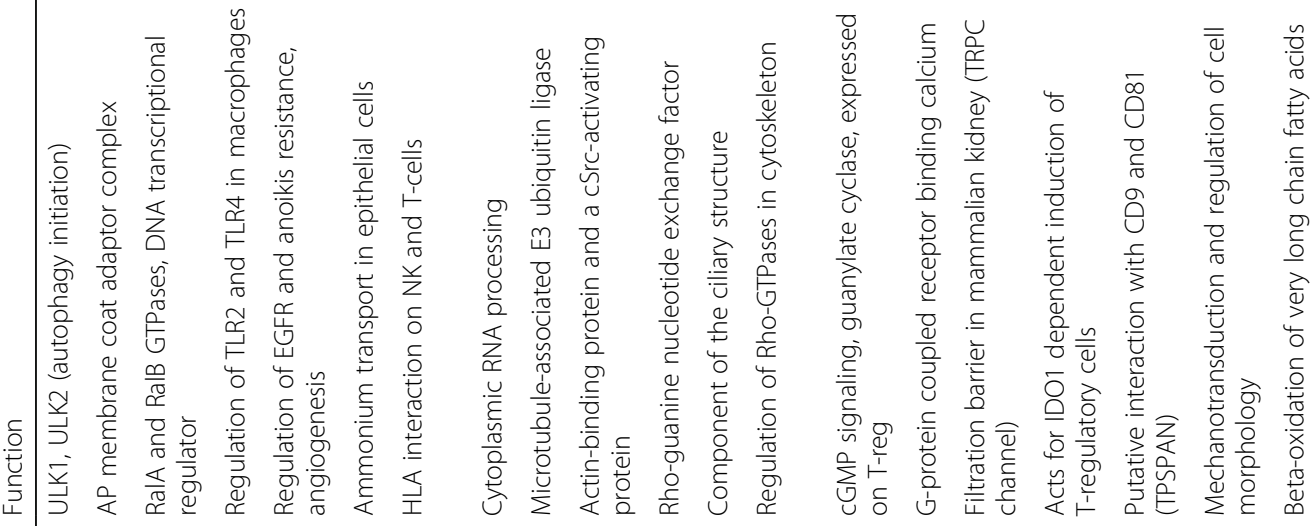

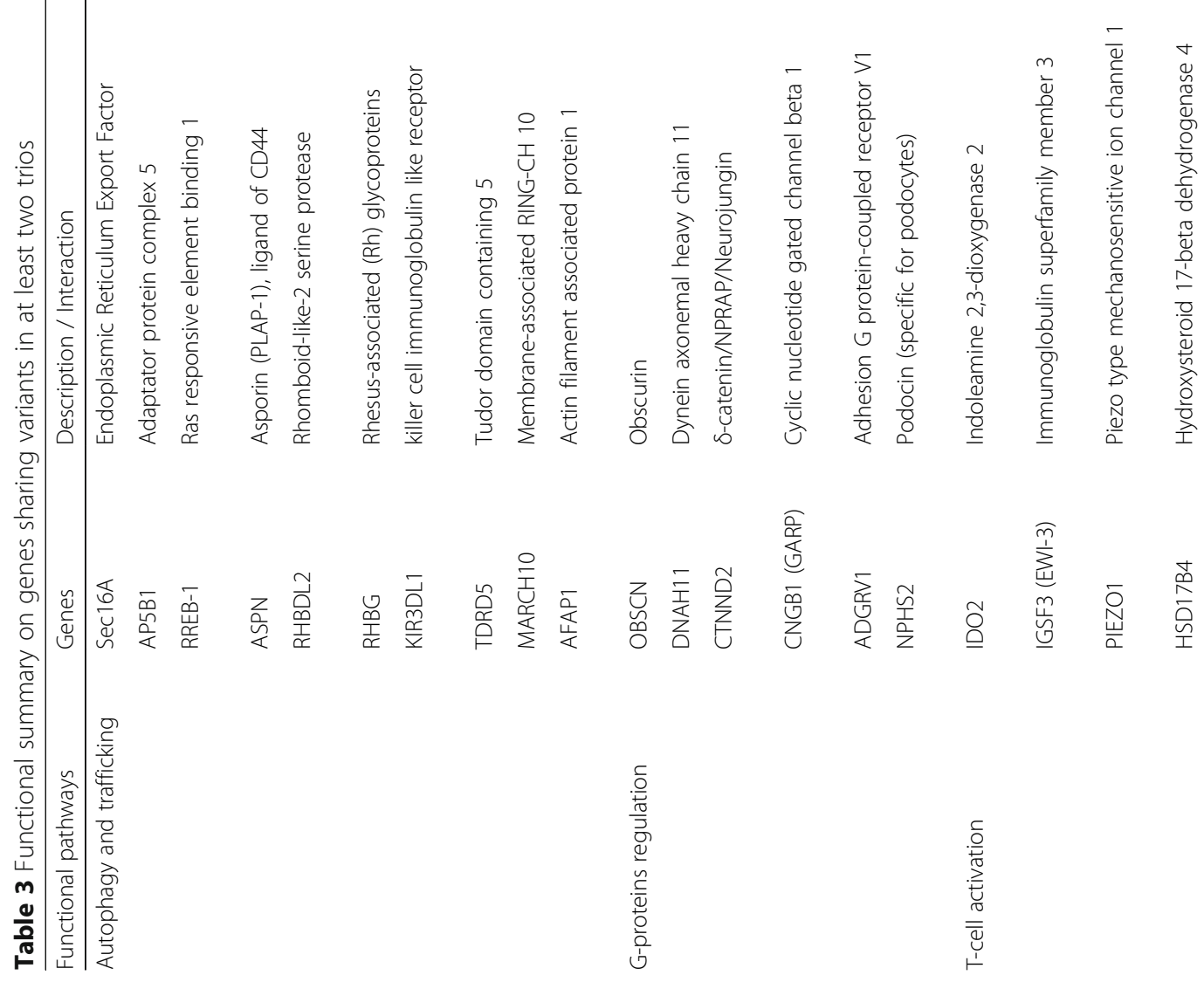




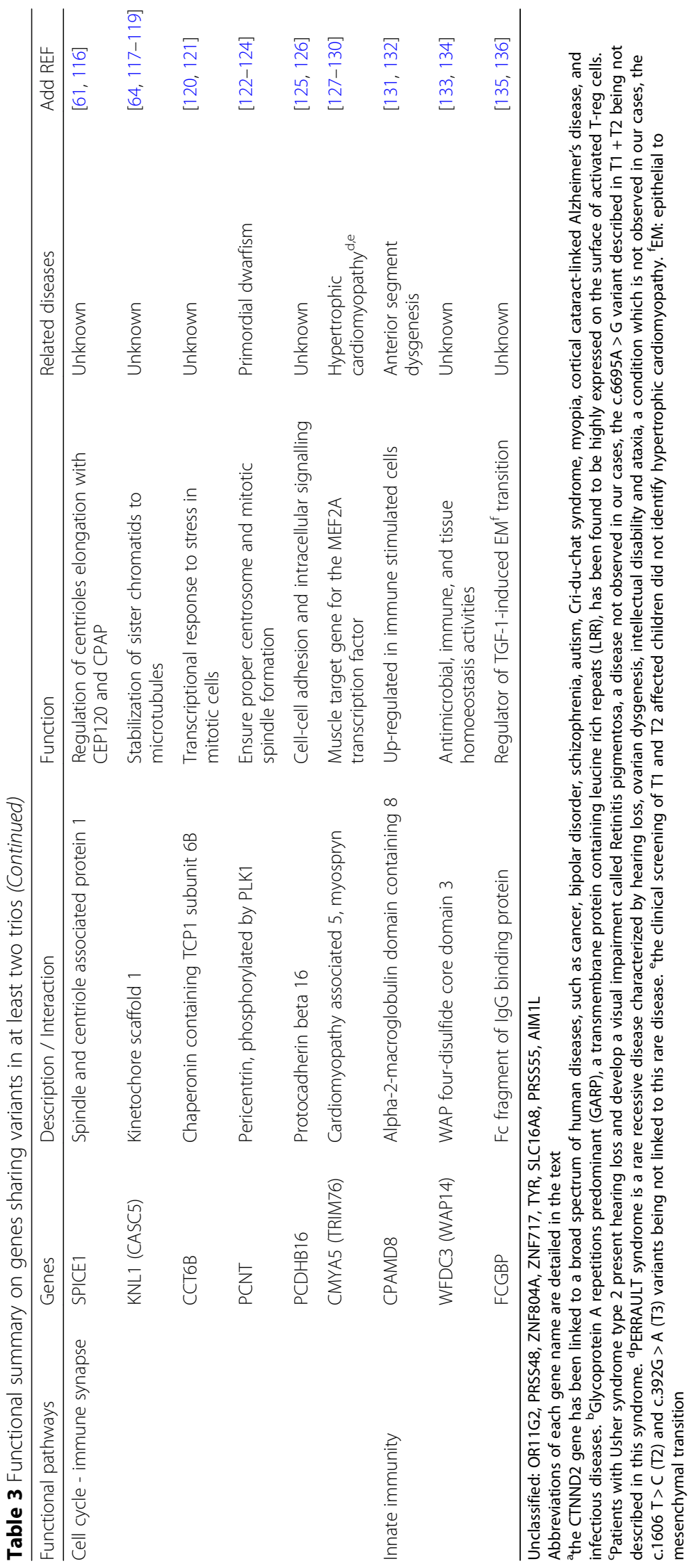


(SPICE1, KNL1, CCT6B, PCNT, PCDHB16 and CMYA5) as regulation factors of transcription, cell cycle and immune synapse, and lastly, three (CPAMD8, WFDC3 and FCGBP) in innate immunity. Eight genes could not be classified. In order to summarize the most relevant data which implicate 4 major pathways that have been related to molecular / cellular defects in granuloma genesis, we presented the data for 10 of the 37 genes identified in this work and served as a basis for discussion of possible underlying pathological mechanisms related to sarcoidosis (Table 4).

\section{Discussion}

Sarcoidosis is a multifactorial disease that involves environmental pathogenic factors on a genetic background. Two sets of observations indicate a strong genetic heterogeneity. First, the rate of familial sarcoidosis remains low (3 to 5\%) with most of the cases being a priori sporadic cases [7]. Second, a wide range of genetic variants have been previously identified by association studies in genes that may play a role in the pathogenesis of sarcoidosis, such as HLA-DP, BTNL2, Annexin A11, Tolllike receptors, CCDC88B (coiled-coil domain containing protein $88 \mathrm{~B}$ ), Ataxin/SH2B adapter protein 3, IL12B and NF-kappa-B p105 subunit $[9,29,30]$. The present work focuses on exceptional pediatric forms in terms of frequency and severity, with affected children having both parents healthy. We designed a WES genetic analysis on trios since a recent study suggested that for unsolved clinical exomes, extensive WES analysis of parent - offspring trios could identify likely contributory variant in $36 \%$ of cases [31]. Such an observation cannot be applied directly to sarcoidosis even if we might expect that comparing the exome of a patient and their healthy parents remains the most powerful strategy which has been used in many multifactorial diseases such in autism-spectrum disorders (ASD). As for ASD, both de novo and recessive variants must be considered as a powerful approach of relevant candidate genes [32]. Of the 37 genes identified in this work, 29 may be related directly or indirectly to pathways linked to immunity and related processes, such as autophagy, intracellular transport, T-cell activation and differentiation, cell cycle and immune synapse. The results obtained were selected according to strict quality criteria, including their reproduction in two independent analyzes, in-house pipeline PASS filtration, high analysis depth and suggestion of in silico pathogenicity in at least one of the software, SIFT or POLYPHENv2. Comparative statistical analysis of the selected variants versus other variants of the same gene showed no significant difference for the SIFT and POLYPHEN scores and a significant result for the CADD score (Additional file 4: Figure S1). The latter integrates several systems for analyzing the pathogenicity of variants and suggests that the variants observed belong to less than $10 \%$ of the most deleterious variants of the genome. However, the data should be analyzed with caution because many frequent polymorphisms in the genome have high SIFT and POLYPHEN scores and the non-parametric test performed in our study is likely to lack power given the small number of selected variants.

The variants and genes were classified in two ways:

First, according to the genetic transmission, we identified 6 de novo variants / mutations in 6 different genes without any overlap between the three affected children (Table 1). Except for IGSF3 and ZNF717, these variants were unknown in databases for SPICE1, CTNND2, NPHS2 and PRSS55 genes. All these heterozygous variants might induce pathogenic events and the function of genes was discussed later except those of ZNF717 and PRSS55 which remain unknown to date. Due to the very large number of variants observed by the WES technique in each of the trios, we then focused only on rare $(\mathrm{MAF}<0.01)$ and recessive variations in each of the children of the trios (Table 2). This concerns 9 variants in 9 genes. A brief functional description for 4 of them (WNT2, COG6, FMNL1, DCP1B) was proposed in relation to immunity related process.

We then focused our attention on more common variants, all MAF values taken together, occurring in at least 2 trios and/or affecting a similar gene between at least two trios. They were classified as true homozygous recessive variants (Additional file 1: Table S1), or occurring in a common gene for at least two trios (Additional file 2: Table S2), and recessive heterozygous composites (Additional file 3: Table S3). This represents a total of 79 coding variants, 58 (73.4\%) of them being putatively considered a pathogenic for the encoded protein by either SIFT and/or Polyphenv2. The integration in our work of common variants was absolutely necessary because sarcoidosis is probably a highly polygenic disease induced by the combined effect of rare pathogenic mutations and common polymorphisms in genes related to immunity.

In a second part, we have attempted a functional classification based on the fact that sarcoidosis as a multifactorial environmental and genetic disease may be related to defects in various subcellular, biochemical and immune targets susceptible to explain granuloma formation. We focused mainly on genes with recurring variants in at least two trios. The data are summarized for the whole series of genes in Table 3. We then detailed the functional discussion on 10 genes for which an interesting link has been identified in the bibliography and likely to suggest a link with the pathophysiology of the granuloma (Table 4). We were able to distinguish 4 functional categories 


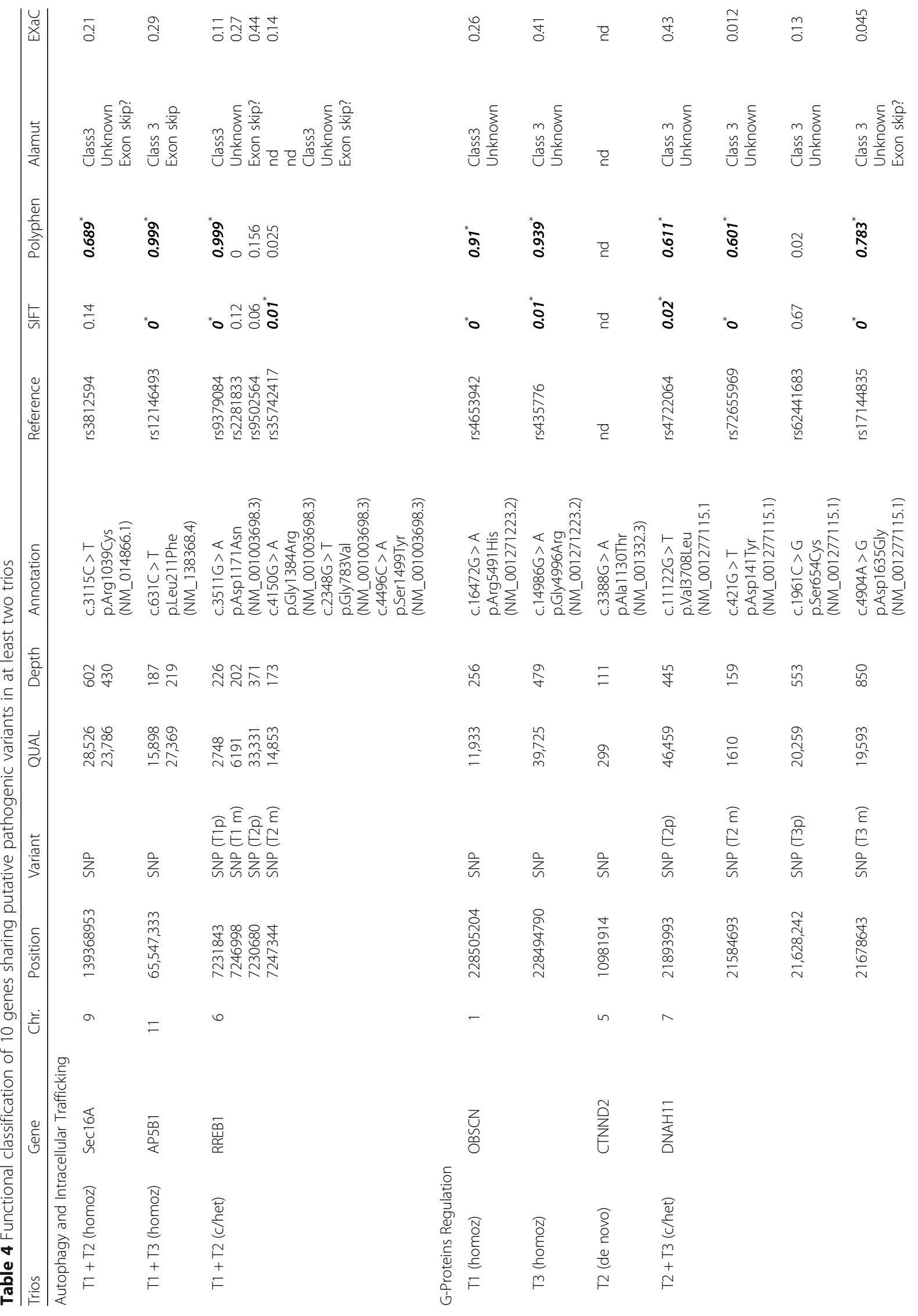




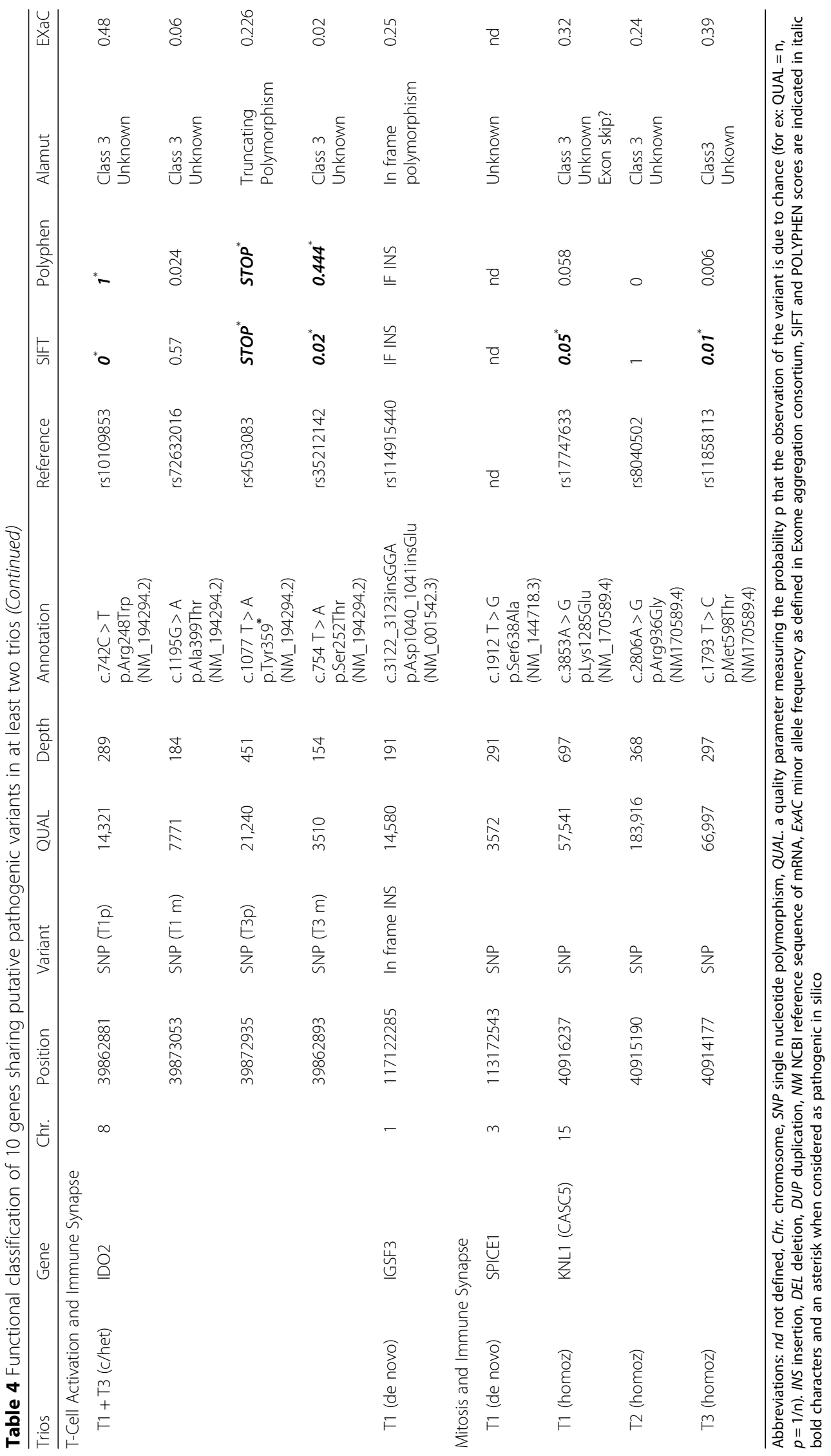




\section{Autophagy and intracellular vesicular trafficking}

In contrast with Crohn's disease, very little information is available on constitutive defects in autophagy for sarcoidosis. These processes are involved in the cellular response to metals and nanoparticles in experimental mice models of granuloma [33, 34]. For instance, Sec16A (affected in T1 + T2) is an interaction partner of ULK1 and ULK2 thought to be essential for initiating autophagy [35]. ULK-mediated phosphorylation of SEC16A regulated the assembly of endoplasmic reticulum (ER) exit sites and ER-to-Golgi trafficking of specific cargo. In frame deletions of SeC16A have been observed in familial forms of spondyloarthritis [36]. AP5B1 (Adaptator protein complex 5), recently implicated in atopic asthma, T1 and T3 share a p.Leu211Phe pathogenic variant [37]. Adaptator proteins sort cargo into vesicles for transport one membrane compartment of the cell to another and AP5 is considered as a candidate for a late endosomal coat, regulating endosomal sorting and vesicle budding from this compartment [38]. COG6, sharing a recessive frame shift mutation in $\mathrm{T} 1$ is a member of the conserved oligomeric Golgi (COG) complex which has been implicated in the regulation of endosome to trans-Golgi network retrograde trafficking [39]. Mutations in the COG genes have been shown to result in the mislocalization of some of the autophagy-related (Atg) proteins, which are critical components involved in autophagosome formation. Interestingly, single nucleotide polymorphisms of the COG6 gene have been recently shown as shared risk locus for rheumatoid arthritis and systemic lupus erythematosus [39]. Another interesting gene is RREB-1 (Ras-responsive elementbinding protein 1), a zinc finger transcription factor, which is an effector of the RaIA/B small GTPases, acting as major regulator in exosome release, membrane trafficking, cytokinesis, cell shape and movement [40].

\section{G-proteins regulation}

When in the GTP-bound active form, Rho GTPases transduce signals by binding to effector proteins involved in many cellular processes including regulation of the actin skeleton, microtubule dynamics, cell division, migration and adhesion [41]. Such a regulation occurs in various immune cells: monocyte/macrophage, $\mathrm{T}$ and $\mathrm{B}$ lymphocytes and neutrophils. The switch between the GDP inactive and GTP active of typical Rho GTPases is regulated by guanine nucleotide exchange factors (GEF) and GTPase-activating proteins (GAP). Rho GTPases are known to exert an effect on the cytoskeleton through NF B, a major player in inflammatory processes [41]. The present study identified genes encoding GTPases or GEF, such as OBSCN and CTNND2. OBSCN (OBSCURIN), mutated in T1 and T3, are giant cytoskeletal proteins with structural and regulatory roles on
Rho-GEF activity and play a role in the maintenance of cell-cell adhesion and regulate epithelial to mesenchymal transition [42]. The $\mathrm{T} 1$ patient shares a rare and recessive variant in FMNL1, encoding one isoform of the formin proteins. Macrophages express multiple formins, including FMNL1, with potential to impact actin remodeling involved in migration [43]. Formins interact with GTP-bound Rho, Rac and Cdc42 GTPases and contribute to macrophage migration activity by stabilizing the lifespan of podosomes, a key actor of actin cytoskeleton dynamics during adhesion and migration within tissues [44, 45]. DCP1B (decapping enzyme 1), mutated in T3, interacts with DEF6, a Rho-family guanine nucleotide exchange factor, which contributes to the regulation of the spatiotemporal organization of components of $\mathrm{T}$ cell signaling pathways and Cdc42-dependent actin polymerization [46]. CTNND2 (Delta Catenin 2), affected by a de novo mutation in $\mathrm{T} 2$, is an adhesive junction-associated protein in the delta subfamily of the $\beta$-catenin superfamily and functions in Wnt signaling pathways to regulate gene expression and modulate Rho GTPases in cytoskeletal reorganization [47]. By regulating the activity of small GTPases and the disruption of E-cadherin based adherens junction, delta catenin 2 promotes cell migration and one might expect that such a process could play a role in macrophage fusion [48]. The observation of an uncommon recessive variant in the WNT2 gene (T1 patient) may be relevant of a pathogenic role of the canonical Wnt/ß-catenin signaling pathway in part of the inflammatory process occurring in sarcoidosis. Two other genes (DNAH11 and RREB1) present compound heterozygotes variants respectively in $(\mathrm{T} 1+\mathrm{T} 2)$ and $(\mathrm{T} 2+\mathrm{T} 3)$ and have been characterized as proteins interacting with small GTPases $[49,50]$.

\section{T-cell activation}

The immune patterns and T-reg cells disturbances observed in sarcoidosis are similar to those observed in other Th1/Th17 related diseases [51]. IDO2 (indoleamine 2,3 dioxygenase) is a particularly interesting gene, as affected by deleterious variants both in T1 and T3 (Table 3). IDO2 is expressed in antigen-presenting cells (APCs), including dendritic cells (DCs) and B cells and deserves special attention by its function in T-cell regulation and differentiation in vitro $[52,53]$. IDO2 may contribute to inflammatory processes by acting in monocyte-derived DCs to control regulatory T-reg cells, as a putative immunosuppressive factor. IDO1 and IDO2 are functional interacting partners and have been associated to various autoimmune states, such as colitis, arthritis and encephalomyelitis [53]. These conflicting results suggest both an immunosuppressive and a positive inflammatory influence [54]. Interestingly, the two variants observed respectively in $\mathrm{T} 1$ (p.Arg248Trp - rs10109853 - MAF =0,353) and T3 
(p.Tyr359* - rs4503083 - MAF $=0,226$ ) are two common inactivating polymorphisms observed in humans [52]. The first, Arg248Trp, introduces a mutation at a catalytic residue that results in $>90 \%$ reduction in catalytic activity in in vitro assays $[52,55]$. The second is a STOP codon at residue 359 , leading to a truncated and catalytically inactive protein product. Based on allele frequencies it estimated that at least $25 \%$ of the population has a functionally inactive IDO2. The two affected children from $\mathrm{T} 1$ and $\mathrm{T} 3$ share a second allelic variant with a putative deleterious suggesting that expression of IDO2 may be dramatically affected in both cases. IDO2 is essential for the IDO1-dependent induction of T-regulatory cells [53]. It can be hypothesized that IDO2, in synergy with IDO1 is both a pro inflammatory factor acting in B lymphocytes to promote the cross talk between $\mathrm{B}$ and $\mathrm{T}$ cells, increasing the number of antibody-secreting cells, thus acting as an immunosuppressive agent by the control of T-reg cells. Inactivating mutations may be responsible for a decrease in the activity and / or number of regulatory Tcells, thereby inducing a pro inflammatory situation. These genes are already being studied as potential therapeutic targets. It has recently been shown that IDO2specific monoclonal antibodies reduced auto reactive $\mathrm{T}$ and $\mathrm{B}$ cell activation and alleviated arthritis in two independent preclinical arthritis models [56]. A de novo variant has been observed in T1 for the IGSF3 gene, an inframe insertion which high frequency $(0,25)$ in control population. The function of IGSF3 may be related to the molecular background of immune synapse, involving members of the immunoglobulin (Ig) superfamily such as BTNL2 [29]. IGSF3 or EWI-3 belongs to a novel Ig subfamily containing a Glu-Trp- Ile (EWI) motif not seen in other Ig proteins and has a strong similarity with CD101, a T-cell marker notably expressed on T-REG with potent suppressor activity, and which expression regulates IL-17 production and disease activity in inflammatory bowel and rheumatoid diseases $[57,58]$.

\section{Cell cycle and immune synapse}

At the crosstalk of innate immunity and the toxicity of environment-derived particles, a strong interest has been shown for a series of molecules that might play a role in promoting granuloma formation. However there is controversy about the molecular and cellular mechanisms generating polyploidy giant cells found in sarcoidosis granuloma. It was thought that these lesions were generated by a cell fusion mechanism; however evidence from other studies suggests that mitotic defects and DNA damage may generate polyploidy in macrophages [59]. Previous works have described elevated numbers of cells in the $\mathrm{S}+\mathrm{G} 2 / \mathrm{M}$ phase in advanced forms of sarcoidosis, suggesting that such mitotic defects may affect different immune cell lineages [60]. In connection with these concepts, we were interested to observe an unknown de novo variant in T1, p.Ser638Ala in the SPICE1 gene which encodes a protein that localizes to spindle microtubules in mitosis and to centrioles throughout the cell cycle [61]. Together with centrosome proteins CEP120 or CPAP, SPICE regulates the elongation of centrioles, which serve as templates for the assembly of centrosome structures [62]. Interestingly, the centrosome plays also a crucial role in the assembly and function of immune synapse and cytokine production during inflammation [63]. We thus might expect that defects in the molecular interaction that impact on the docking of centrosome at the plasma membrane initiated by T-cell and APC interaction is a relevant process related to innate immunity. On the other hand, experimental depletion of SPICE1 causes severe mitotic defects [61]. KNL1 (CASC5), a kinetochore substrate of Aurora-B, share putative pathogenic variants in the three trios (Table 2). This gene has been involved in the stabilization of sister chromatids to microtubules during mitosis, maintenance of centromeres cohesion and regulation of mitotic checkpoint silencing $[64,65]$.

\section{Conclusions}

Using a WES approach in pediatric forms of sarcoidosis and parent - offspring trios we have identified a panel of genes that led us to propose hypotheses about 4 functional pathways potentially mediating the underlying mechanism(s) of granuloma formation: autophagy related intracellular vesicular trafficking, G-protein signaling and Rho GTPases, immune synapse and T-cell activation, and lastly intimate mechanisms of cell cycle and mitosis regulation. An over-representation gene enrichment KEGG pathway analysis suggests that a significant number of genes selected belongs to pathways related to Antigen processing and presentation and that of the hematopoietic cell lineage We are aware that this study is of descriptive type and that some of the selected variants may have no direct role in the development of the disease. Nevertheless, these results fit with the fact that sarcoidosis is a multifactorial disease with a complex genetic background and agree the hypothesis of multiple and combined mechanisms in the genesis of the granuloma. Clinically, it is possible that the variable expressivity of the disease can be explained by a strong genetic heterogeneity, in particular between the different evolutionary forms. Further studies are awaited to compare gene variants identified in pediatric cases and autosomal dominant family forms. The characterization of a very broad panel of genes associated with the different clinical forms of sarcoidosis will ultimately not only define the relative risk of disease occurrence in families at risk, but also better characterize the evolutionary profiles and help to optimize therapeutic strategies. 


\section{Additional files}

Additional file 1: Table S1. Recessive variants found in at least two affected children of different trios. Possibly pathogenic recessive variants (polymorphisms) found by whole-exome -sequencing in at least two affected children of the trios (T). Chr., chromosome; SNP, single nucleotide polymorphism; QUAL., a quality parameter measuring the probability $\mathrm{p}$ that the observation of the variant is due to chance (for ex: $Q U A L=n, p=1 / n$ ). As detailed in the text, Alamut ${ }^{\oplus}$ Visual integrates missense variant pathogenicity prediction tools and in silico study of variants' effect on RNA splicing, allowing the assessment of their potential impact on splice junctions and splicing regulatory sequences. Alamut ${ }^{\circledR} \mathrm{Visual}$ helped us also to exclude well known mutations identified in recessive diseases for those genes which have been related to known genetic diseases (as shown in Table 3). (DOCX 23 kb)

Additional file 2: Table S2. Recessive variants shared by a common gene in at least two different trios. Possibly pathogenic recessive variants observed at different positions for a single gene in at least two affected children of the trios (T). Abbreviations are the same as in Tables 1, 2 and Additional file 1: Table S1. (DOCX $31 \mathrm{~kb}$ )

Additional file 3: Table S3. Composite heterozygocity observed in a common gene in at least two different trios. Possibly pathogenic compound heterozygous variants (allelic heterogeneity) observed in different positions of a common gene in at least two trios. The origin of either the paternal and maternal allele was detailed for each variant. Abbreviations are the same as in Tables 1, 2, Additional files 1 and 2: Tables S1 and S2. (DOCX 51 kb)

Additional file 4: Figure S1. CADD scoring of prioritized variants versus other variants in the selected genes. (PDF $71 \mathrm{~kb}$ )

Additional file 5: Table S4. Over-representation gene enrichment KEGG pathway analysis was performed on all the deleterious variant carrying genes. Data of the over-representation gene enrichment KEGG pathway analysis was performed on all the deleterious variant carrying genes in trios 1, 2 and 3. (XLSX 9 kb)

Additional file 6: All recessive variants identified in cases $\mathrm{T} 1, \mathrm{~T} 2$ and $\mathrm{T}$. The de novo dominant variants have been fully described in the manuscript. The datasets of cases T1, T2 and T3 extracted from VCF (Variant call Format) and extracted in XLS file. (XLSX 368 kb)

\section{Abbreviations}

1000G: 1000 genomes; BTNL2: Butyrophilin like 2; CCDC88B: Coiled-coil domain containing protein 88b; CPP: Comité de Protection des Personnes; $\mathrm{CT}$ : Computed tomography; ESP: Exome sequencing project; ExAC: Exome aggregation consortium; GTP/GDP: guanine tri/diphosphate; GWAS: Genome wide association studies; MAF: Minr allele frequency; mTor: Mammalian target of rapamycin; NOD2: Nucleotide binding oligomerization domain containing 2; Polyphenv2: Polymorphism Phenotyping v2; QPCR: Quantitative polymerase chain reaction; SARCFAM: Familial sarcoidosis; SIFT: Sorting Intolerant From Tolerant; SNP: Single nucleotide polymorphism; STAT1: Signal transducer and activator of transcription 1; TSC1/2: Tuberous sclerosis; XAF1: $X$ inhibitor of apoptosis associated factor 1

\section{Acknowledgments}

We thank the families for their kind participation and continued interest in this study. We thank Raphaelle LAMY and Céline AUBOIROUX for expert technical assistance. We thank Mrs. Dr. Janet Hall for reviewing this manuscript. This work has been performed in the frame of a national clinical and research group working on sarcoidosis, Group Sarcoidosis France (GSF).

\section{Funding}

This study was performed with the grant named 'High Throughput sequencing and rare disease' from the "Fondation Maladies Rares" (FMR - France) and financial support from the INNOVARC - DGOS ref. 12-027-0309.

\section{Availability of data and materials}

The datasets (Variant call Format extracted in XLS file) supporting the discussion of this article are available are presented in Additional file 6.

\section{Authors' contributions}

Conceived and designed the experiments: AC (1), AB (1) and SP. Performed the experiments: cooperative projects with IntegraGen SA (c) (Evry, France). Analyzed the data: AC, PARF, SP, YP, AB (2), CB, PR, and SL. Wrote the paper: $A C, Y P$ and NN. Provided the clinical cases and data: NN, HC, RAT, VH, DV

GD, VC, PS, AC (2) and JFB. All authors read and approved the final manuscript.

\section{Ethics approval and consent to participate}

This project has been approved by the ethical committee (CPP LYON SUD EST - 2 - REF IRB 00009118 - September 21, 2016), according to the Laws Nos. 94-548 of 1 July 1994, Nos. 94-653 and 94-654 of 29 July 1994, taking into account the amendments further introduced by the laws $n^{\circ} 2004-800$ of 6 August 2004 and $n{ }^{\circ}$ 2011-814 of 7 July 2011, both relating to bioethics. This approval included an informed consent form and a detailed information sheet for patients. According to the article R. 1131-4 of the French Public Health Code, for the participants who are under $18 \mathrm{yr}$., the consent has been given by both mother and father during clinical and genetic counseling. In the three cases, there were the natural parents which have the parental authority. In addition, the consent of the minor is systematically sought if he is able to express his will and participate in the decision. The clinical and genetic studies were registered by the ClinicalTrials.gov- Protocol Registration and Results System (PRS) receipt under the reference NCT02829853.

\section{Consent for publication}

The SARCFAM protocol was presented to the ethical committee (CPP LYON SUD EST - 2 - REF IRB 00009118) dated September 21, 2016 and includes consent for genetic studies and an information document on the objectives of genetic analysis and the scientific SARCFAM project. This document is an informed consent for the publication of scientific and clinical data subject to a complete anonymity of the information. Our study does not present any photographic data. This informed consent is valid for adult patients and for children $(<18 \mathrm{yr})$ after signature of both legal parents.

\section{Competing interests}

The authors declare that they have no competing interests.

\section{Publisher's Note}

Springer Nature remains neutral with regard to jurisdictional claims in published maps and institutional affiliations.

\section{Author details}

${ }^{1}$ Genetics Department, Hospices Civils de LYON (HCL), University Hospital, East Pathology Center, LYON, B-A3, 59 Bld Pinel, 69677 BRON Cedex, France. ${ }^{2}$ Department of biostatistics, University Hospital, Hospices Civils de LYON $(\mathrm{HCL})$, Lyon, France. ${ }^{3}$ Inflammation \& Immunity of the Respiratory Epithelium - EA7426 (PI3) - South Medical University Hospital - Lyon 1 Claude Bernard University, 165 Chemin du Grand Revoyet, 69310 Pierre-Bénite, France. ${ }^{4}$ Cancer Research Center, INSERM U-1052, CNRS 5286, 69008 Lyon, France. ${ }^{5}$ Pediatric pulmonology and Reference Center for rare lung diseases RespiRare, Hôpital Trousseau, AP-HP, INSERM UMR-S938, Sorbonne University, Paris, France. ${ }^{6}$ Pediatric pulmonology and Reference Center for rare lung diseases RespiRare, Hôpital Necker, Paris, France. ${ }^{7}$ Pediatric pulmonology and Reference Center for rare lung diseases RespiRare, Hôpital Robert Debré, INSERM U-1142, University Paris Diderot VII, Paris, France. ${ }^{8}$ Department of Pulmonology, University Hospital, Hôpital Croix Rousse, Lyon, France. ${ }^{9}$ Department of Pulmonology, University Hospital, Hôpital Louis Pradel, Lyon, France. ${ }^{10}$ Department of Internal medicine, University Hospital, Hôpital Croix Rousse, Lyon, France. ${ }^{11}$ Histology and Tumor Biology, ER2 UPMC, Hôpital Tenon, Paris, France. ${ }^{12}$ Medical University of Vienna, Center for Pathobiochemistry and Genetics, Institute of Medical Genetics, Währinger Straße 10, 1090 Vienna, Austria. ${ }^{13}$ EA2363, University Paris 13, COMUE Sorbonne-Paris-Cité, 74 rue Marcel Cachin, 93009 Bobigny, France.

${ }^{14}$ Assistance Publique Hôpitaux de Paris, Department of Pulmonology, Avicenne University Hospital, 93009 Bobigny, France. ${ }^{15}$ AP-HP Pediatric pulmonology and Reference Center for rare lung diseases RespiRare, Hôpital Trousseau, INSERM UMR-S933, Sorbonne University, Paris, France. 


\section{Received: 13 August 2017 Accepted: 19 February 2018} Published online: 06 March 2018

\section{References}

1. Valeyre D, Prasse A, Nunes H, Uzunhan Y, Brillet PY, Müller-Quernheim J. Sarcoidosis. Lancet. 2014;383:1155-67.

2. Chen ES, Moller DR. Etiologies of sarcoidosis. Clin Rev Allergy Immunol. 2015;49:6-18.

3. Nathan N, Marcelo P, Houdoin V, Epaud R, de Blic J, Valeyre D, et al. Lung sarcoidosis in children: update on disease expression and management. Thorax. 2015;70:537-42.

4. Nathan N, Taam RA, Epaud R, Delacourt C, Deschildre A, Reix P, et al. (French RespiRare ${ }^{\oplus}$ group) a national internet-linked based database for pediatric interstitial lung diseases: the French network. Orphanet J Rare Dis. 2012;7:40-8.

5. Baughman RP, Lower EE. Frequency of acute worsening events in fibrotic pulmonary sarcoidosis patients. Respir Med. 2013;107:2009-13.

6. Swale VJ, Spector TD, Bataille VA. Sarcoidosis in monozygotic twins. Br J Dermatol. 1998;139:350-2.

7. Pacheco Y, Calender A, Israël-Biet D, Roy P, Lebecque S, Cottin V, et al. Familial vs. sporadic sarcoidosis: BTNL2 polymorphisms, clinical presentations, and outcome in a French cohort (GSF). Orphanet J Rare Dis. 2016;11:165-73.

8. Lin Y, Wei J, Fan L, Cheng D. BTNL2 gene polymorphism and sarcoidosis susceptibility : a meta-analysis. PLoS One. 2015;10 https://doi.org/10.1371/ journal.pone.0122639.

9. Fischer A, Rybicki BA. Granuloma genes in sarcoidosis: what is new ? Curr Opin Pulm Med. 2015;21:510-6.

10. Timmermans WM, van Laar JA, van Hagen PM, van Zelm MC Immunopathogenesis of granulomas in chronic auto inflammatory diseases. Clin Transl Immunology. 2016;5 https:/doi.org/10.1038/cti.2016.75.

11. Facco M, Cabrelle A, Teramo A, Olivieri V, Gnoato M, Teolato S, et al. Sarcoidosis is a Th1/Th17 multisystem disorder. Thorax. 2011;66:144-50.

12. Broos CE, Hendriks RW, Kool M. T-cell immunology in sarcoidosis: disruption of a delicate balance between helper and regulatory T-cells. Curr Opin Pulm Med. 2016:22:476-83.

13. Hu Y, Yibrehu B, Zabini D, Kuebler WM. Animal models of sarcoidosis. Cell Tissue Res. 2017:367:651-61.

14. Lee $S$, Barber L, Kanchwala A, Childs CJ, Kataria YP, Judson MA, et al. Low levels of NF-kB/p65 mark anergic CD4+ T cells and correlate with disease severity in sarcoidosis. Clin Vaccine Immunol. 2011;18:223-4.

15. Rosenbaum JT, Pasadhika S, Crouser ED, Choi D, Harrington CA, Lewis JA, et al. Hypothesis: sarcoidosis is a STAT1-mediated disease. Clin Immunol. 2009; 132:174-83.

16. Nemoz G, Prigent AF, Aloui R, Charpin G, Gormand F, Gallet H, et al. Impaired G-proteins and cyclic nucleotide phosphodiesterase activity in T-lymphocytes from patients with sarcoidosis. Eur J Clin Investig. 1993;23:18-27.

17. Talreja J, Talwar H, Ahmad N, Rastogi R, Samavati L. Dual inhibition of Rip2 and IRAK1/4 regulates $\mathrm{IL}-1 \beta$ and IL-6 in sarcoidosis alveolar macrophages and peripheral blood mononuclear cells. J Immunol. 2016;197:1368-78.

18. Linke M, Thanh Pham HT, Katholnig K, Schnöller T, Miller A, Demel F, et al. Chronic signaling via the metabolic checkpoint mTORC1 induces macrophage granuloma formation and masks sarcoidosis progression. Nat Immunol. 2017;18:293-302.

19. Viprey M, Donadieu J, Epaud R, Coulomb A, le Pointe HD, Clement A, et al. Massive splenomegaly and pancytopenia revealing sarcoidosis in a child. Sarcoidosis Vasc Lung Dis. 2013;30:149-52.

20. Gnirke A, Mmelnikov A, Maguire J, Rogov P, leProust EM, Brockman W, et al. Solution hybrid selection with ultra-long oligonucleotides for massively parallel targeted sequencing. Nat Biotech. 2009;27:182-9.

21. Ng PC, Henikoff S. SIFT : predicting amino acid changes that affect protein function. Nucleic Acids Res. 2003:31:3812-4.

22. Adzhubei I, Jordan DM, Sunyaev SR. Predicting functional effect of human missense mutations using PolyPhen-2. Curr Protoc Hum Genet. 2013; Chapter 7:7-20.

23. Raponi M, Kralovicova J, Copson E, Divina P, Eccles D, Johnson P, et al. Prediction of single-nucleotide substitutions that result in exon skipping: identification of a splicing silencer in BRCA1 exon 6. Hum Mutat. 2011;32:436-44.

24. Liu X, Wu C, Li C, Boerwinkle E. dbNSFP v3.0: a one-stop database of functional predictions and annotations for human non-synonymous and splice site SNVs. Hum Mutat. 2016;37(3):235-41.
25. Kircher M, Witten DM, Jain P, O'Roak BJ, Cooper GM, Shendure J. A general framework for estimating the relative pathogenicity of human genetic variants. Nat Genet. 2014;46:310-5.

26. Wang J, Vasaikar S, Shi Z, Greer M, Zhang B. WebGestalt 2017: a more comprehensive, powerful, flexible and interactive gene set enrichment analysis toolkit. Nucleic Acids Res. 2017;45(Web Server issue):W130-7.

27. Leutenegger AL, Prum B, Genin E, Verny C, Lemainque A, Clerget-Darpoux $F$, Thompson EA. Estimation of the inbreeding coefficient through use of genomic data. Am J Hum Genet. 2003;73:516-23.

28. Gazal S, Sahbatou M, Babron MC, Génin E, Leutenegger AL. FSuite: exploiting inbreeding in dense SNP chip and exome data. Bioinformatics. 2014;30:1940-1.

29. Valentonyte R, Hampe J, Huse K, Rosenstiel P, Albrecht M, Stenzel A, et al Sarcoidosis is associated with a truncating splice site mutation in BTNL2. Nat Genet. 2005:37:357-64.

30. Fischer A, Schmid B, Ellinghaus D, Nothnagel M, Gaede Kl, Schürmann M, et al. A novel sarcoidosis risk locus for Europeans on chromosome 11q13.1. Am J Respir Crit Care Med. 2012;186:877-85.

31. Eldomery MK, Coban-Akdemir Z, Harel T, Rosenfeld JA, Gambin T, StrayPedersen $A$, et al. Lessons learned from additional research analyses of unsolved clinical exome cases. Genome Med. 2017;9 https://doi.org/10. 1186/s13073-017-0412-6

32. Jiang $Y H$, Yuen RCK, Jin X, Wang $M$, Chen N, Wu X, et al. Detection of clinically relevant genetic variants in autism spectrum disorders by wholegenome sequencing. Am J Hum Genet. 2013;93:249-63.

33. Chatterjee S, Sarkar S, Bhattacharya S. Toxic metals and autophagy. Chem Res Toxicol. 2014;27(11):1887-900.

34. Xia L, Gu W, Zhang M, Chang YN, Chen K, Bai X, et al. Endocytosed nanoparticles hold endosomes and stimulate binucleated cells formation. Part Fibre Toxicol. 2016:13:63.

35. Joo JH, Wang B, Frankel E, Ge L, Xu L, lyengar $R$, et al. The noncanonical role of ULKVATG1 in ER-to-Golgi trafficking is essential for cellular homeostasis. Mol Cell. 2016;62:491-506.

36. O'Rielly DD, Uddin M, Codner D, Hayley M, Zhou J, Pena-Castillo L, et al. Private rare deletions in SEC16A and MAMDC4 may represent nove pathogenic variants in familial axial spondylo arthritis. Ann Rheum Dis. 2016; 75:772-9.

37. Hirst J, Barlow LD, Francisco GC, Sahlender DA, Seaman MN, Dacks JB, et al. The fifth adaptor protein complex. PLoS Biol. 2011;10:e1001170. https://doi. org/10.1371/journal.pbio.1001170. Epub 2011 Oct 11

38. Laufman $\mathrm{O}$, Hong W, Lev S. The COG complex interacts directly with Syntaxin 6 and positively regulates endosome-to-TGN retrograde transport. J Cell Biol. 2011:194:459-72.

39. Márquez A, Vidal-Bralo L, Rodríguez-Rodríguez L, González-Gay MA, Balsa A, González-Álvaro I, et al. A combined large-scale meta-analysis identifies COG6 as a novel shared risk locus for rheumatoid arthritis and systemic lupus erythematosus. Ann Rheum Dis. 2017:76:286-94.

40. Zago G, Biondini M, Camonis J, Parrini MC. A family affair: a Ral-exocystcentered network links Ras, Rac, rho signaling to control cell migration. Small GTPases. 2017;12:1-8. https://doi.org/10.1080/21541248.

41. Tong $\mathrm{L}$, Tergaonkar $\mathrm{V}$. Rho protein GTPases and their interactions with NFkB: crossroads of inflammation and matrix biology. Biosci Rep. 2014;34(3): e00115. https://doi.org/10.1042/BSR20140021.

42. Perry NA, Vitolo MI, Martin SS, Kontrogianni-Konstantopoulos A. Loss of the obscurin-RhoGEF downregulates RhoA signaling and increases microtentacle formation and attachment of breast epithelial cells. Oncotarget. 2014;5:8558-68

43. Miller MR, Blystone SD. Human macrophages utilize the Podosome Formin FMNL1 for adhesion and migration. Cell. 2015;4:1-11.

44. Kühn S, Geyer M. Formins as effector proteins of rho GTPases. Smal GTPases. 2014:5:e29513-1-15.

45. Miller MR, Miller EW, Blystone SD. Non-canonical activity of the podosomal formin FMNL1y supports immune cell migration. J Cell Sci. 2017;130:1730-9.

46. Hey F, Czyzewicz N, Jones P, Sablitzky F. DEF6, a novel substrate for the Tec kinase ITK, contains a glutamine-rich aggregation-prone regions and forms cytoplasmic granules that co-localize with P-bodies. J Biol Chem. 2012:287:31073-84

47. Lu Q, Aguilar BJ, Li M, Jiang Y, Chen YH. Genetic alterations of $\delta$-catenin/ NPRAP/Neurojungin (CTNND2): functional implications in complex human diseases. Hum Genet. 2016;135:1107-16.

48. Helming L, Gordon S. Molecular mediators of macrophage fusion. Trends Cell Biol. 2009;10:514-22. 
49. Oxford G, Smith SC, Hampton G, Theodorescu D. Expression profiling of Raldepleted bladder cancer cells identifies RREB-1 as a novel transcriptional Ral effector. Oncogene. 2007;26:7143-52.

50. Capala ME, Maat H, Bonardi F, van den Boom V, Kuipers J, Vellenga E, et al. Mitochondrial dysfunction in human leukemic stem/progenitor cells upon loss of RAC2. Plos One. 2015;27 https://doi.org/10.1371/journal.pone.0128585.

51. Georas SN, Chapman TJ, Crouser ED. Sarcoidosis and T-helper cells. Th1, Th17, or Th17.1? Am J Respir Crit Care Med. 2016 Jun 1;193(11):1198-200.

52. Merlo LM, Mandik-Nayak L. IDO2: a pathogenic mediator of inflammatory autoimmunity. Clin Med Insights Pathol. 2016;9(Suppl 1):21-8.

53. Metz R, Smith C, DuHadaway JB, Chandler P, Baban B, Merlo LM, et al. IDO2 is critical for IDO1-mediated T-cell regulation and exerts a non-redundant function in inflammation. Int Immunol. 2014;26:357-67.

54. Metz R, Duhadaway JB, Kamasani U, Laury-Kleintop L, Muller AJ, Prendergast GC. Novel tryptophan catabolic enzyme IDO2 is the preferred biochemical target of the antitumor indoleamine 2,3-dioxygenase inhibitory compound D-1-methyl-tryptophan. Cancer Res. 2007;67:7082-7.

55. Merlo LM, Grabler S, DuHadaway JB, Pigott E, Manley K, Prendergast GC, et al. Therapeutic antibody targeting of indoleamine-2,3-dioxygenase (IDO2) inhibits autoimmune arthritis. Clin Immunol. 2017;179:8-16.

56. Jovanovic DV, Boumsell L, Bensussan A, Chevalier X, Di Battista JA. CD101 expression and function in normal and rheumatoid arthritis-affected human T-cells and monocytes/macrophages. J Rheumatol. 2011;38:419-28.

57. Schey R, Dornhoff H, Baier JL, Purtak M, Opoka R, Koller AK, et al. CD101 inhibits the expansion of colitogenic T-cells. Mucosal Immunol. 2016;9:1205-17.

58. Herrtwich L, Nanda I, Evangelou K, Nikolova T, Horn V, Sagar, et al. DNA damage signaling instructs Polyploid macrophage fate in granulomas. Cell. 2016;167:1264-80.

59. Pacheco Y, Cordier G, Perrin-Fayolle M, Revillard JP. Flow cytometry analysis of T lymphocytes in sarcoidosis. Am J Med. 1982;73:82-8.

60. Archinti M, Lacasa C, Teixidó-Travesa N, Lüders J. SPICE: a previously uncharacterized protein required for centriole duplication and mitotic chromosome congression. J Cell Sci. 2010;123:3039-46.

61. Comartin D, Gupta GD, Fussner E, Coyaud E, Hasegan M, Archinti M, et al. CEP120 and SPICE1 cooperate with CPAP in centriole elongation. Curr Biol. 2013;23:1360-6.

62. Vertii A, Ivshina M, Zimmerman W, Hehnly H, Kant S, Doxsey S. The centrosome undergoes Plk1-independent interphase maturation during inflammation and mediates cytokine release. Dev Cell. 2016;37:377-86.

63. Prendergast GC, Metz R, Muller AJ, Merlo LM, Mandik-Nayak L. IDO2 in immunomodulation and autoimmune disease. Front Immunol. 2014;5:585-94.

64. Ghongane P, Kapanidou M, Asghar A, Elowe S, Bolanos-Garcia VM. The dynamic protein Knl1 - a kinetochore rendezvous. J Cell Sci. 2014;127:3415-23.

65. Zhang G, Kruse T, Lopez-Mendez B, Sylvestersen KB, Garvanska DH, Schopper $\mathrm{S}$, et al. Bub1 positions Mad1 close to KNL1 MELT repeats to promote checkpoint signalling. Nat Commun. 2017:8:15822. https://doi.org/10.1038/ ncomms 15822.

66. Cho HJ, Yu J, Xie C, Rudrabhatla P, Chen X, Wu J, et al. Leucine-rich repeat kinase 2 regulates Sec16A at ER exit sites to allow ER-Golgi export. EMBO J. 2014;33:2314-31

67. Zuo X, Sun L, Yin X, Gao J, Sheng Y, Xu J, et al. Whole-exome SNP array identifies 15 new susceptibility loci for psoriasis. Nat Commun. 2015;6:6793. doi: 10.1038

68. Marenholz I, Esparza-Gordillo J, Rüschendorf F, Bauerfeind A, Strachan DP, Spycher BD, et al. Meta-analysis identifies seven susceptibility loci involved in the atopic march. Nat Commun. 2015;6:8804. doi: 10.1038

69. Thiagalingam A, De Bustros A, Borges M, Jasti R, Compton D, Diamond L, et al. RREB-1, a novel zinc finger protein, is involved in the differentiation response to Ras in human medullary thyroid carcinomas. Mol Cell Biol. 1996;16:5335-45.

70. Flajollet S, Poras I, Carosella ED, Moreau P. RREB-1 is a transcriptional repressor of HLA-G. J Immunol. 2009;183:6948-59.

71. Ming L, Wilk R, Reed BH, Lipshitz HD. Drosophila hindsight and mammalian RREB-1 are evolutionarily conserved DNA-binding transcriptional attenuators. Differentiation. 2013;86:159-70.

72. Nakamura T, Shi D, Tzetis M, Rodriguez-Lopez J, Miyamoto Y, Tsezou A, et al. Meta-analysis of association between the ASPN D-repeat and osteoarthritis. Hum Mol Genet. 2007;16:1676-8.

73. Ding Q, Zhang M, Liu C. Asporin participates in gastric cancer cell growth and migration by influencing EGF receptor signaling. Oncol Rep. 2015;33:1783-90.
74. Awata T, Yamada S, Tsushima K, Sakashita H, Yamaba S, Kajikawa T, et al. PLAP1/Asporin positively regulates FGF-2 activity. J Dent Res. 2015;94:1417-24.

75. Yamaba S, Yamada S, Kajikawa T, Awata T, Sakashita H, Tsushima K, et al. PLAP-1/Asporin regulates TLR2- and TLR4-induced inflammatory responses. J Dent Res. 2015;94:1706-14.

76. Adrain C, Strisovsky K, Zettl M, Hu L, Lemberg MK, Freeman M. Mammalian EGF receptor activation by the rhomboid protease RHBDL2. EMBO Rep. 2011;12:421-7.

77. Cheng TL, Lai CH, Jiang SJ, Hung JH, Liu SK, Chang BI, Shi GY, et al. RHBDL2 is a critical membrane protease for anoikis resistance in human malignant epithelial cells. Sci World J. 2014:902987. doi: 10.1155

78. Noy PJ, Swain RK, Khan K, Lodhia P, Bicknell R. Sprouting angiogenesis is regulated by shedding of the C-type lectin family 14, member a (CLEC14A) ectodomain, catalyzed by rhomboid-like 2 protein (RHBDL2). FASEB J. 2016:30:2311-23.

79. Han KH, Mekala K, Babida V, Kim HY, Handlogten ME, Verlander JW, et al. Expression of the gas-transporting proteins, Rh B glycoprotein and Rh C glycoprotein, in the murine lung. Am J Phys Lung Cell Mol Phys. 2009:297:L153-63.

80. Caner T, Abdulnour-Nakhoul S, Brown K, Islam MT, Hamm LL, Nakhoul NL. Mechanisms of ammonia and ammonium transport by rhesus-associated glycoproteins. Am J Phys Cell Phys. 2015;309:C747-58.

81. Díaz-Peña R, Vidal-Castiñeira JR, Alonso-Arias R, Suarez-Alvarez B, Vicario JL, Solana $\mathrm{R}$, et al. Association of the KIR3DS1*013 and KIR3DL1*004 alleles with susceptibility to ankylosing spondylitis. Arthritis Rheum. 2010;62:1000-6.

82. Petrushkin H, Hasan MS, Stanford MR, Fortune F, Wallace GR. Behçet's disease: do natural killer cells play a significant role? Front Immunol. 2015;6:134-41.

83. Ahn RS, Moslehi H, Martin MP, Abad-Santos M, Bowcock AM, Carrington M, et al. Inhibitory KIR3DL1 alleles are associated with psoriasis. Br J Dermatol. 2016;174:449-51.

84. Callebaut I, Mornon JP. LOTUS, a new domain associated with small RNA pathways in the germline. Bioinformatics. 2010;26:1140-4.

85. Patil VS, Anand A, Chakrabarti A, Kai T. The Tudor domain protein tapas, a homolog of the vertebrate Tdrd7, functions in the piRNA pathway to regulate retrotransposons in germline of Drosophila melanogaster. BMC Biol. 2014;12:61. doi: 10.1186

86. lyengar PV, Hirota T, Hirose S, Nakamura N. Membrane-associated RING-CH 10 (MARCH10 protein) is a microtubule-associated E3 ubiquitin ligase of the spermatid flagella. J Biol Chem. 2011;286:39082-90.

87. Nakamura N. The role of the transmembrane RING finger proteins in cellular and organelle function. Membranes. 2011;1:354-93.

88. Snyder BN, Cho Y, Qian Y, Coad JE, Flynn DC, Cunnick JM. AFAP1L1 is a novel adaptor protein of the AFAP family that interacts with cortactin and localizes to invadosomes. Eur J Cell Biol. 2011;90:376-89.

89. Cunnick JM, Kim S, Hadsell J, Collins S, Cerra C, Reiser P, Flynn DC, Cho Y. Actin filament-associated protein 1 is required for cSrc activity and secretory activation in the lactating mammary gland. Oncogene. 2015;34:2640-9.

90. Cho Y, Silverstein R, Geisinger MT, Martinkovich S, Corkill H, Cunnick JM, Planey SL, Arnott JA. AFAP1 is a novel downstream mediator of TGF- $\beta 1$ for CCN2 induction in osteoblasts. PLoS One. 2015;10:e0136712. doi: 10.1371

91. Ford-Speelman DL, Roche JA, Bowman AL, Bloch RJ. The rho-guanine nucleotide exchange factor domain of obscurin activates rhoA signaling in skeletal muscle. Mol Biol Cell. 2009:20:3905-17.

92. Manring HR, Carter OA, Ackermann MA. Obscure functions: the locationfunction relationship of obscurins. Biophys Rev. 2017; doi: 10.1007

93. Bartoloni L, Blouin JL, Pan Y, Gehrig C, Maiti AK, Scamuffa N, et al. Mutations in the DNAH11 (axonemal heavy chain dynein type 11) gene cause one form of situs inversus totalis and most likely primary ciliary dyskinesia. Proc Natl Acad Sci U S A. 2002;99:10282-6.

94. Knowles MR, Leigh MW, Carson JL, Davis SD, Dell SD, Ferkol TW, et al. Mutations of DNAH11 in patients with primary ciliary dyskinesia with normal ciliary ultrastructure. Thorax. 2012;67:433-41.

95. Dougherty GW, Loges NT, Klinkenbusch JA, Olbrich H, Pennekamp P, Menchen $\mathrm{T}$, et al. DNAH11 localization in the proximal region of respiratory cilia defines distinct outer dynein arm complexes. Am J Respir Cell Mol Biol. 2016:55:213-24

96. Turner TN, Sharma K, Oh EC, Liu YP, Collins RL, Sosa MX, et al. Loss of $\delta$ catenin function in severe autism. Nature. 2015;520:51-6.

97. Michalakis S, Reisert J, Geiger H, Wetzel C, Zong X, Bradley J, et al. Loss of CNGB1 protein leads to olfactory dysfunction and subciliary cyclic nucleotide-gated channel trapping. J Biol Chem. 2006;281:35156-66. 
98. Zhang Y, Molday LL, Molday RS, Sarfare SS, Woodruff ML, Fain GL, et al. Knockout of GARPs and the $\beta$-subunit of the rod cGMP-gated channel disrupts disk morphogenesis and rod outer segment structural integrity. J Cell Sci. 2009;122:1192-200.

99. Paquet-Durand F, Beck S, Michalakis S, Goldmann T, Huber G, Mühlfriedel R, et al. A key role for cyclic nucleotide gated (CNG) channels in CGMP-related retinitis pigmentosa. Hum Mol Genet. 2011;20:941-7.

100. Elkord E, Abd Al Samid M, Chaudhary B. Helios, and not FoxP3, is the marker of activated Tregs expressing GARP/LAP. Oncotarget. 2015;6:20026-36.

101. Hamann J, Aust G, Araç D, Engel FB, Formstone C, Fredriksson R, et al. International Union of Basic and Clinical Pharmacology. XCIV. Adhesion G protein-coupled receptors. Pharmacol Rev. 2015;67:338-67.

102. Zou J, Chen Q, Almishaal A, Mathur PD, Zheng T, Tian C, et al. The roles of USH1 proteins and PDZ domain-containing USH proteins in USH2 complex integrity in cochlear hair cells. Hum Mol Genet. 2017;26:624-36.

103. Roselli S, Moutkine I, Gribouval O, Benmerah A, Antignac C. Plasma membrane targeting of podocin through the classical exocytic pathway: effect of NPHS2 mutations. Traffic. 2004;5:37-44.

104. Huber TB, Schermer B, Müller RU, Höhne M, Bartram M, Calixto A, et al. Podocin and MEC-2 bind cholesterol to regulate the activity of associated ion channels. Proc Natl Acad Sci U S A. 2006;103:17079-86.

105. Guaragna MS, Lutaif AC, Piveta CS, Souza ML, de Souza SR, Henriques TB, et al. NPHS2 mutations account for only $15 \%$ of nephrotic syndrome cases. BMC Med Genet. 2015;16:88. doi: 10.1186

106. Merlo LM, DuHadaway JB, Grabler S, Prendergast GC, Muller AJ, MandikNayak L. IDO2 modulates T cell-dependent autoimmune responses through a B cell-intrinsic mechanism. J Immunol. 2016;196:4487-97.

107. Stipp CS, Kolesnikova TV, Hemler ME. EWI-2 is a major CD9 and CD81 partner and member of a novel lg protein subfamily. J Biol Chem. 2001;276:40545-54

108. Clark KL, Zeng Z, Langford AL, Bowen SM, Todd SC. PGRL is a major CD81associated protein on lymphocytes and distinguishes a new family of cell surface proteins. J Immunol. 2001;167:5115-21.

109. Sakamoto S, Qin J, Navarro A, Gamero A, Potla R, Yi T, Zhu W, Baker DP, Feldman G, Larner AC. Cells previously desensitized to type 1 interferons display different mechanisms of activation of stat-dependent gene expression from naïve cells. J Biol Chem. 2004;279:3245-53.

110. Usardi A, lyer K, Sigoillot SM, Dusonchet A, Selimi F. The immunoglobulinlike superfamily member IGSF3 is a developmentally regulated protein that controls neuronal morphogenesis. Dev Neurobiol. 2017;77:75-92.

111. Coste B, Mathur J, Schmidt M, Earley TJ, Ranade S, Petrus MJ, Dubin AE, Patapoutian A. Piezo1 and Piezo2 are essential components of distinct mechanically activated cation channels. Science. 2010;330:55-60.

112. Bagriantsev SN, Gracheva EO, Gallagher PG. Piezo proteins: regulators of mechanosensation and other cellular processes. J Biol Chem. 2014;289:31673-81.

113. Gudipaty SA, Lindblom J, Loftus PD, Redd MJ, Edes K, Davey CF, Krishnegowda V, Rosenblatt J. Mechanical stretch triggers rapid epithelial cell division through Piezo1. Nature. 2017;543:118-21.

114. Pierce SB, Walsh T, Chisholm KM, Lee MK, Thornton AM, Fiumara A, et al. Mutations in the DBP-deficiency protein HSD17B4 cause ovarian dysgenesis, hearing loss, and ataxia of Perrault syndrome. Am J Hum Genet. 2010;87:282-8.

115. Procaccini C, Carbone F, Di Silvestre D, Brambilla F, De Rosa V, Galgani M, et al. The proteomic landscape of human ex vivo regulatory and conventional $T$ cells reveals specific metabolic requirements. Immunity. 2016;44:406-21.

116. Gupta GD, Coyaud E, Gonçalves J, Mojarad BA, Liu Y, Wu Q, et al. A dynamic protein interaction landscape of the human centrosome-cilium interface. Cell. 2015;163(6):1484-99.

117. Cheeseman IM, Hori T, Fukagawa T, Desai A. KNL1 and the CENP-H/I/K complex coordinately direct kinetochore assembly in vertebrates. Mol Biol Cell. 2008:19:587-94.

118. Tanaka K. Regulatory mechanisms of kinetochore-microtubule interaction in mitosis. Cell Mol Life Sci. 2013;70:559-79.

119. Bollen M. Kinetochore signalling: the Klss that MELTs Knl1. Curr Biol. 2014;24:R68-70

120. Kubota H, Hynes GM, Kerr SM, Willison KR. Tissue-specific subunit of the mouse cytosolic chaperonin-containing TCP-1. FEBS Lett. 1997:402:53-6.

121. Kaisari S, Sitry-Shevah D, Miniowitz-Shemtov S, Teichner A, Hershko A. Role of CCT chaperonin in the disassembly of mitotic checkpoint complexes. Proc Natl Acad Sci U S A. 2017;114:956-61.

122. Rauch A, Thiel CT, Schindler D, Wick U, Crow YJ, Ekici AB, et al. Mutations in the pericentrin (PCNT) gene cause primordial dwarfism. Science. 2008;319:816-9.
123. Chen CT, Hehnly H, Yu Q, Farkas D, Zheng G, Redick SD, et al. A unique set of centrosome proteins requires pericentrin for spindle-pole localization and spindle orientation. Curr Biol. 2014;24:2327-34.

124. Luo Y, Pelletier L. Pericentrin: critical for spindle orientation. Curr Biol. 2014;24:R962-4

125. Junghans D, Heidenreich M, Hack I, Taylor V, Frotscher M, Kemler R. Postsynaptic and differential localization to neuronal subtypes of protocadherin beta16 in the mammalian central nervous system. Eur J Neurosci. 2008:27:559-71.

126. Phillips GR, LaMassa N, Nie YM. Clustered protocadherin trafficking. Semin Cell Dev Biol. 2017:S1084-9521(17):30244-6. doi: 10.1016

127. Durham JT, Brand OM, Arnold M, Reynolds JG, Muthukumar L, Weiler H, et al. Myospryn is a direct transcriptional target for MEF2A that encodes a striated muscle, alpha-actinin-interacting, costamere-localized protein. J Biol Chem. 2006:281:6841-9.

128. Sarparanta J. Biology of myospryn: what's known? J Muscle Res Cell Motil. 2008:29:177-80

129. Tsoupri E, Capetanaki Y. Myospryn: a multifunctional desmin-associated protein. Histochem Cell Biol. 2013;140:55-63.

130. Jiang MX, Hong $X$, Liao BB, Shi SZ, Lai XF, Zheng HY, et al. Expression profiling of TRIM protein family in THP1-derived macrophages following TLR stimulation. Sci Rep. 2017:7:42781. Published online 2017 Feb 17. doi: 10.1038

131. Li ZF, Wu XH, Engvall E. Identification and characterization of CPAMD8, a novel member of the complement 3/alpha2-macroglobulin family with a Cterminal Kazal domain. Genomics. 2004;83:1083-93.

132. Cheong SS, Hentschel L, Davidson AE, Gerrelli D, Davie R, Rizzo R, et al. Mutations in CPAMD8 cause a unique form of autosomal-recessive anterior segment dysgenesis. Am J Hum Genet. 2016;99:1338-52.

133. Hagiwara K, Kikuchi T, Endo Y, Huqun, Usui K, Takahashi M, et al. Mouse SWAM1 and SWAM2 are antibacterial proteins composed of a single whey acidic protein motif. J Immunol. 2003;170:1973-9.

134. Ferreira Z, Seixas S, Andrés AM, Kretzschmar WW, Mullikin JC, Cherukuri PF, et al. Reproduction and immunity-driven natural selection in the human WFDC locus. Mol Biol Evol. 2013;30(4):938-50.

135. Xiong $L$, Wen $Y$, Miao X, Yang Z. NT5E and FcGBP as key regulators of TGF1 -induced epithelial-mesenchymal transition (EMT) are associated with tumor progression and survival of patients with gallbladder cancer. Cell Tissue Res. 2014;355:365-74.

136. Lang T, Klasson S, Larsson E, Johansson ME, Hansson GC, Samuelsson T. Searching the evolutionary origin of epithelial mucus protein componentsmucins and FCGBP. Mol Biol Evol. 2016;33:1921-36.

\section{Submit your next manuscript to BioMed Central and we will help you at every step:}

- We accept pre-submission inquiries

- Our selector tool helps you to find the most relevant journal

- We provide round the clock customer support

- Convenient online submission

- Thorough peer review

- Inclusion in PubMed and all major indexing services

- Maximum visibility for your research

Submit your manuscript at www.biomedcentral.com/submit 